\title{
A transient heat transfer model for high temperature solar thermochemical reactors
}

Like Li ${ }^{1,}$, , Chen Chen ${ }^{1}$, Abhishek Singh ${ }^{1}$, Nima Rhamatian ${ }^{1}$, Nick AuYeung ${ }^{2}$, Kelvin Randhir $^{1}$, Renwei Mei ${ }^{1,}{ }^{*}$, James F. Klausner ${ }^{1,}{ }^{*}$, David W. Hahn ${ }^{1}$, Jörg Petrasch ${ }^{3}$

${ }^{1}$ Department of Mechanical and Aerospace Engineering, University of Florida, Gainesville, FL 32611, USA

${ }^{2}$ School of Chemical, Biological and Environmental Engineering, Oregon State University, Corvalis, OR 97331, USA

${ }^{3}$ Energy Research Center, Vorarlberg University of Applied Sciences, 6850 Dornbirn, Austria

* Corresponding authors; e-mail addresses: likelichina@ufl.edu (L. Li), rwmei@ufl.edu (R. Mei), klaus@ufl.edu (J. Klausner).

\begin{abstract}
We present a heat transfer model for energy transport in a solar thermochemical reactor for $\mathrm{CO}_{2}$ and/or $\mathrm{H}_{2} \mathrm{O}$ splitting to produce chemical fuels $\mathrm{CO}$ and/or $\mathrm{H}_{2}$. The reactor is comprised of a horizontal cavity-receiver packed with several insulation layers, an array of tubular absorbers in which the reactive metal oxide is loaded, and a windowless aperture that allows the incident concentrated solar energy to enter the receiver. A framework for modeling the complex multimode thermal transport within the reactor system is developed. The concentrated solar radiation from a high flux solar simulator to the cavity-receiver is simulated using a Monte-Carlo ray tracing model. Heat transfer within the tubular absorbers, including conduction, convection, radiation, and chemical reactions, is simulated using a lattice Boltzmann (LB) model. These two models are coupled by taking into account the temperature-dependent radiative emission from the absorber surfaces. Two particular techniques are employed to improve the numerical accuracy and stability: appropriate rescaling of the relaxation coefficients in the LB method and implicit treatment of the heat source/sink terms due to chemical reactions. The numerical method is validated with two test cases for which analytical solutions are available. Simulation results for the heating process and one
\end{abstract}


thermal reduction step under near-vacuum pressures are presented. The predicted solar-to-fuel energy conversion efficiency varies from $5 \%$ to $10 \%$ and is determined based on the simulated $\mathrm{O}_{2}$ release during the reduction step. The model is able to provide insight into the optimum operating conditions, the reactor design and the scale-up. The results suggest that high temperatures for both reduction and oxidation steps and near-vacuum pressure $\left(\sim 10^{-4} \mathrm{~atm}\right)$ for thermal reduction are critical for improved solar-to-fuel conversion efficiency with the ceria-based reactive material.

Keywords: Solar reactor, thermochemical fuel production, heat transfer, Monte-Carlo ray tracing, lattice Boltzmann.

\section{Introduction}

Solar energy, especially concentrated solar thermal energy, has vast potential to contribute towards a more sustainable and clean energy portfolio. Storing solar thermal energy chemically as a fuel is of enormous interest. In the last decade, metal oxide reduction-oxidation (redox) cycles have been intensively studied as chemical loops for fuel production. Two-step $\mathrm{CO}_{2}$ and $\mathrm{H}_{2} \mathrm{O}$ splitting redox processes can be generally represented as

$$
\begin{aligned}
& \text { Thermal reduction: } \mathrm{MO}_{x} \rightarrow \mathrm{MO}_{x-y}+\frac{y}{2} \mathrm{O}_{2}, \\
& \mathrm{CO}_{2} \text { splitting oxidation: } \mathrm{MO}_{x-y}+y \mathrm{CO}_{2} \rightarrow \mathrm{MO}_{x}+y \mathrm{CO} \text {, and } \\
& \mathrm{H}_{2} \mathrm{O} \text { splitting oxidation: } \mathrm{MO}_{x-y}+y \mathrm{H}_{2} \mathrm{O} \rightarrow \mathrm{MO}_{x}+y \mathrm{H}_{2},
\end{aligned}
$$

where the metal oxide is thermally reduced at high temperatures to a lower oxidation state (Reaction (1)), then oxidized using $\mathrm{CO}_{2}$ and/or $\mathrm{H}_{2} \mathrm{O}$ to form $\mathrm{CO}$ and/or $\mathrm{H}_{2}$ (Reactions (2a, 2b)). $\mathrm{CO}$ and $\mathrm{H}_{2}$ in tandem, also known as syngas, can be a precursor to synthetic liquid fuels such as jet fuel, gasoline, or diesel [1]. Though very attractive, economic viability will require welldesigned energy conversion devices to maximize the overall conversion efficiency. This will in 
turn minimize costs associated with the concentrating solar radiation and the reactor hardware necessary per unit of fuel [2].

A solar thermochemical reactor typically features a cavity-type receiver that captures the concentrated solar energy, and a small open or windowed aperture that allows the sunlight to travel through while minimizing the re-radiation from the receiver. The orientation of the cavity with regard to the incoming concentrated sunlight can be either horizontal or vertical, i.e., the axis of the cavity is either parallel or perpendicular to the centerline of the concentrated sunlight. Active cooling is usually required for a quartz window, and its optical properties such as absorptivity would be affected during multiple cycles as the gases in the cavity may condense on and contaminate the window $[3,4]$. The reactive materials are in the forms of porous beds such as packed particles or stabilized porous structures that have high surface area for chemical reaction during the extensive cycling process. The reactive beds are either directly exposed to the incident radiation, or packed in tubular absorbers and indirectly irradiated by the solar flux. The engineering design of a reactor requires a functional model to account for heat transfer, species transport, and chemical reaction. Heat transfer in the cavity-reactor system includes radiation, conduction, convection and endothermic/exothermic chemical reactions. Effective modeling of the heat transfer and energy transport in the solar reactor is essential to the reactor design and it also provides valuable insight and guidance for optimizing operating conditions.

A limited number of lab-scale solar reactor prototypes with solar input power in the range of 3 to $10 \mathrm{~kW}_{\text {th }}$ for fuel production have been designed, computationally modeled, and experimentally tested worldwide. High flux solar simulators using an array of argon or xenon arc lamps $[5,6]$ have been used to provide a radiant source for those high temperature solar reactors. 
An even more limited number of solar reactors on the order of $100 \mathrm{~kW}_{\text {th }}$ to $1 \mathrm{MW}_{\text {th }}$ scales have been tested on-sun.

Schunk et al. [4] presented a reactor design with three-dimensional (3D) computational fluid dynamics (CFD) modeling and experimental testing of a $10 \mathrm{~kW}$ rotating, windowed, horizontal, directly heated cavity-reactor for thermal dissociation of $\mathrm{ZnO}$. The key design concept of the rotating cavity is that the layer of $\mathrm{ZnO}$ particles serves three functions simultaneously: as a radiant absorber, chemical reactants, and a thermal insulator. Müller et al. [7] developed a transient heat transfer model to simulate the coupled radiation, convection, conduction and endothermic reaction in a directly-irradiated solar reactor for thermal dissociation of a $\mathrm{ZnO}$ bed. They validated their model by comparing simulated temperature profiles and reaction rates with measured ones. Abanades et al. [8] designed and simulated a windowed, horizontal, directly heated solar chemical reactor for continuous dissociation of metal oxides, which were continuously injected into the cavity through a screw feeder and a rotating driving gear at the backside of the cavity. Kaneko et al. [9] developed and tested a windowed, rotary-type solar reactor for a two-step $\mathrm{H}_{2} \mathrm{O}$-splitting process using reactive ceramics of ceria and $\mathrm{Ni}$, Mn-ferrite $\left(\mathrm{Ni}_{0.5} \mathrm{Mn}_{0.5} \mathrm{Fe}_{2} \mathrm{O}_{4}\right)$. A simulation of the rotary-type solar reactor was conducted by Kaneko et al. [9] and the solar reactor was tested with $20 \mathrm{~kW}$ input [10]. Diver et al. [11] designed a windowed, vertical-direct counter-rotating-ring receiver/reactor/recuperator (CR5) as a heat engine for solar thermochemical $\mathrm{H}_{2} \mathrm{O}$-splitting. The CR5 uses a stack of counter-rotating rings or disks with fins along the perimeter. The efficacy of the CR5 has been demonstrated by Miller et al. [12] through laboratory and on-sun testing using cobalt ferrite/zirconia mixtures as reactive materials. Ceria-based material was also tested and both $\mathrm{CO}_{2}$ and $\mathrm{H}_{2} \mathrm{O}$-splitting have been demonstrated using the CR5. Roeb et al. [13] built and tested a quasi-continuously 
operating horizontal reactor consisting of two separate chambers with fixed honeycomb absorbers for more than 50 cycles. While $\mathrm{H}_{2} \mathrm{O}$ splitting was taking place in one chamber, thermal reduction was in progress in the other chamber, so that a continuous production of $\mathrm{H}_{2}$ is feasible. They also developed a transient $2 \mathrm{D}$ numerical model to simulate the heat transfer and $\mathrm{H}_{2}$ production in the solar reactor using inputs from experimental measurements. Based on their experimental test and simulation results, they also designed a $100 \mathrm{~kW}_{\text {th }}$ solar pilot plant. Experimental testing of the pilot plant for the two-step $\mathrm{H}_{2} \mathrm{O}$ splitting via monolithic honeycomb solar reactors has been operated within a solar tower [14]. Chueh et al. [15] investigated thermochemical dissociation of $\mathrm{CO}_{2}$ and $\mathrm{H}_{2} \mathrm{O}$ using nonstoichiometric ceria. A total of 500 redox cycles in an infrared furnace were conducted, and four consecutive $\mathrm{CO}_{2}$ and $\mathrm{H}_{2} \mathrm{O}$ cycles were performed in a vertical cavity-receiver reactor for which solar-to-fuel efficiencies of $0.7 \%$ to $0.8 \%$ were achieved. They showed that the efficiencies were largely limited by the system scale and design rather than by chemistry. Using a very similar solar reactor but with a reticulated porous ceramic (RPC) foam made of pure ceria, Furler et al. [16] reported an improved average solar-to-fuel efficiency of $1.73 \%$ for CO production. The RPC foam had a relatively larger density and porosity that enabled high mass loading and volumetric absorption of solar radiation, respectively. More than 200 stable redox cycles were performed recently by Marxer et al. [17] in a similar cavity-receiver. Koepf et al. [18] designed, modeled, and tested a windowed, beamdown, horizontal-direct solar thermochemical receiver/reactor for the reduction of $\mathrm{ZnO}$ particles. An axisymmetric heat transfer model and a CFD vortex-flow model were developed to simulate the reactor. Lapp et al. [19] designed and modeled a windowed, horizontal, directly-irradiated, counter-rotating solar thermochemical reactor for syngas production from $\mathrm{CO}_{2}$ and $\mathrm{H}_{2} \mathrm{O}$ splitting via ceria-based redox cycling. The outer rotating cylinder consists of a reactive porous medium 
cycling between reduction and oxidation; while the inner counter-rotating cylinder is a chemically inert heat recuperating solid. Martinek and Weimer [20] developed a 3D steady-state computational model coupling fluid flow, heat transfer, chemical reaction kinetics and mass transfer to investigate the solar-to-chemical efficiency for a multiple tube solar reactor. The basic reactor configuration is a windowed, vertical, indirectly-irradiated cavity receiver with an array of tubular absorbers arranged in a semicircle around the back wall of the circular cavity. Villasmil et al. [21] improved the transient model [7] with a more detailed radiative heat transfer analysis, combining the Monte-Carlo ray tracing technique and the radiosity enclosure theory. Their simulation results were compared with experimental results of a $10 \mathrm{~kW}$ solar reactor prototype with regard to cavity and quartz window temperatures and $\mathrm{ZnO}$ dissociation extents. Solar-to-fuel efficiency values at different mean $\mathrm{ZnO}$ bed temperatures were computed and compared with 6 experimental runs. The highest experimentally obtained efficiency was $0.16 \%$ for an average bed temperature of $1822 \mathrm{~K}$ and a solar input power of $9.0 \mathrm{~kW}$. They also showed from simulation results a potential of achieving $7 \%$ efficiency for an optimized $10 \mathrm{~kW}$ solar reactor at bed temperatures of $2100 \mathrm{~K}$ under steady-state conditions. Bader et al. [22] presented a $3 \mathrm{~kW}$ prototype solar reactor design to implement isothermal redox cycling of ceria for $\mathrm{CO}_{2}$ splitting. The reactor concept consists of a cylindrical cavity which contains an array of tubular alumina tubes. The mm-sized porous ceria particles were loaded in the tubes and indirectly heated by the solar flux. Thermal and thermo-mechanical models for the reactor and the tubes were developed, and it was predicted that the target steady-state temperature of $1773 \mathrm{~K}$ in the reactor can be reached with acceptably low thermo-mechanical stresses in the tubes. Furler and Steinfeld [23] developed a coupled 3D heat transfer and CFD model for the thermal reduction of a RPC foam made of ceria in a solar reactor described in $[15,16]$. Validation of the model was 
accomplished in terms of measured temperatures and $\mathrm{O}_{2}$ rates in a prototype reactor tested with 2.8-3.8 $\mathrm{kW}$ high-flux radiative power. The model was then applied to analyze an improved design with a conical-shaped cavity, for which more uniform radiative absorption and temperature distributions and increased solar-to-fuel efficiencies of 5.4\% (without heat recovery) and $6.4 \%$ (with heat recovery) were predicted.

In this work, we present a transient 3D model for a $10 \mathrm{~kW}_{\text {th }}$ solar reactor for $\mathrm{H}_{2}$ and $\mathrm{CO}$ production that has been developed at the University of Florida (UF). The reactor design and the simplified computational domain are provided in Section 2. Section 3 focuses on the MonteCarlo ray tracing (MCRT) model for the radiation transport from the solar simulator to the cavity-reactor, and the radiative transfer between the surfaces inside the cavity. Section 4 describes the lattice Boltzmann (LB) based heat transfer model coupling conduction, convection, radiation and endothermic/exothermic reactions in the porous reactive beds inside the absorbers arranged in the cavity. Heat conduction inside the insulation layers and the front and back plates (see Figs. 1 and 2) is also simulated by the LB model. Detailed simulation results for the UF solar reactor are presented in Section 5, in which the rescaling technique in the LB model is validated first, followed by representative results of the heat flux and temperature distributions, chemical reaction rates and fuel production, and the predicted solar-to-fuel efficiencies. Section 6 concludes the paper and suggests future areas of emphasis for modeling solar thermochemical reactors.

\section{Solar reactor design}

A nominal $10 \mathrm{~kW}_{\text {th }}$ windowless, horizontal, indirectly-irradiated solar thermochemical reactor for $\mathrm{H}_{2}$ and syngas production from two-step $\mathrm{CO}_{2}$ and $\mathrm{H}_{2} \mathrm{O}$ splitting has been designed, 
fabricated and is currently under experimental testing [24, 25]. The horizontal cylindrical cavity absorbs the concentrated solar power from the UF High Flux Solar Simulator (HFSS) through a windowless aperture. An array of 14 cylindrical tubular absorbers is arranged at the circumference of the cavity. Reactive materials are loaded in the tubes with one end closed, and indirectly heated by the solar power.

A schematic depiction of the UF solar reactor is shown in Fig. 1. Some key dimensions for the reactor are given in Table 2 in Section 5. A coupled model is developed to simulate the radiation, conduction, and chemical reaction in the solar reactor. The simplified computational domain in the present model is shown in Fig. 2. The model is decomposed into two modules: the cavity-receiver module for radiation transfer between the surfaces in the cavity, and the absorberreactor module for heat conduction, radiation and chemical reaction in the 14 tubes with reactive materials and heat conduction in the insulation layers. These two modules are coupled in each time marching step. Simulation results for the heating process and the first thermal reduction step are presented.

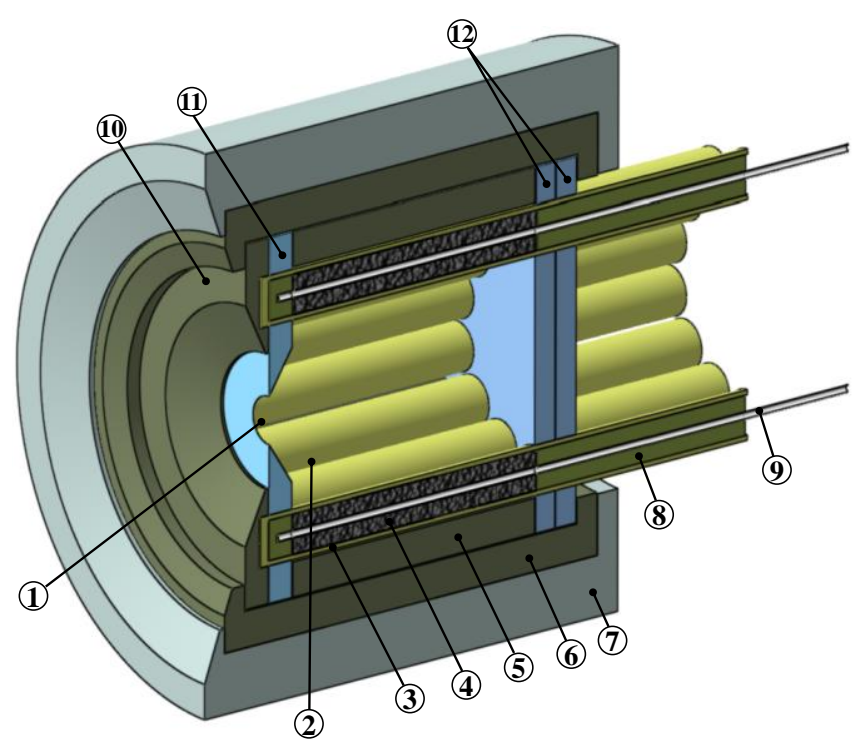

Fig. 1. Schematic depiction of the UF windowless horizontal solar thermochemical reactor: (1) aperture, (2) cavity, (3) alumina tube, (4) packed bed of ceria particles, (5) inner insulation layer (made from alumina Buster M-15, see Table 1 for material properties), (6) center insulation layer 
(Buster M-15), (7) outer microporous insulation layer, (8) insulation blanket (Buster Blanket), (9) center alumina tube, (10) outer front plate (Buster M-15), (11) inner front plate (Buster M35), and (12) back plates (Buster M-35).

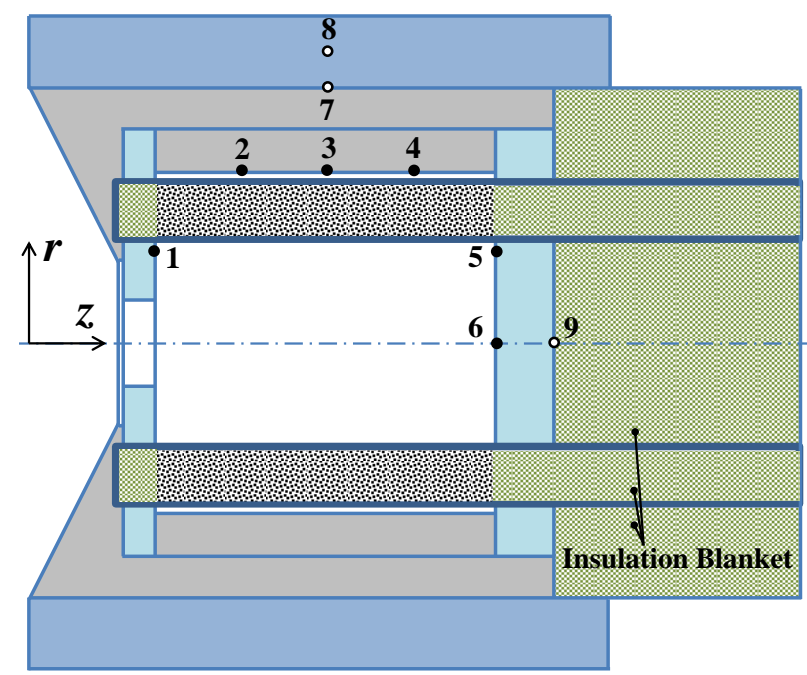

(a)

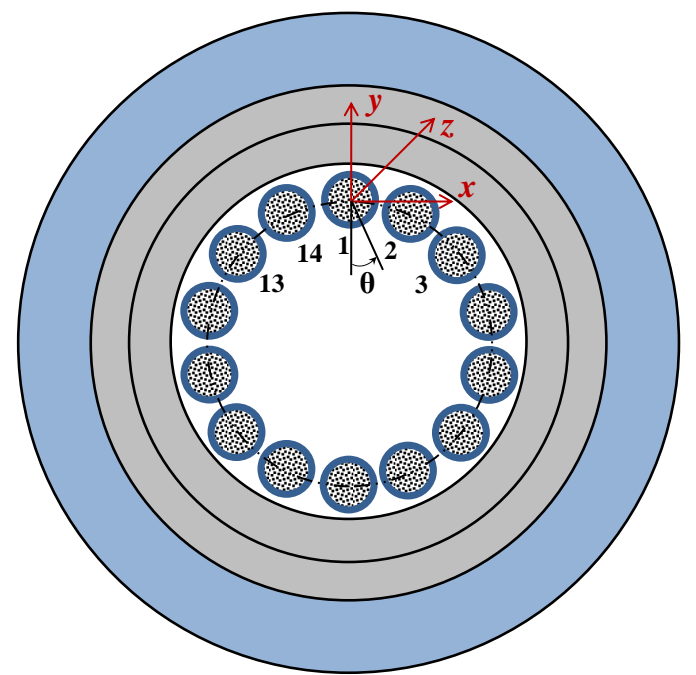

(b)

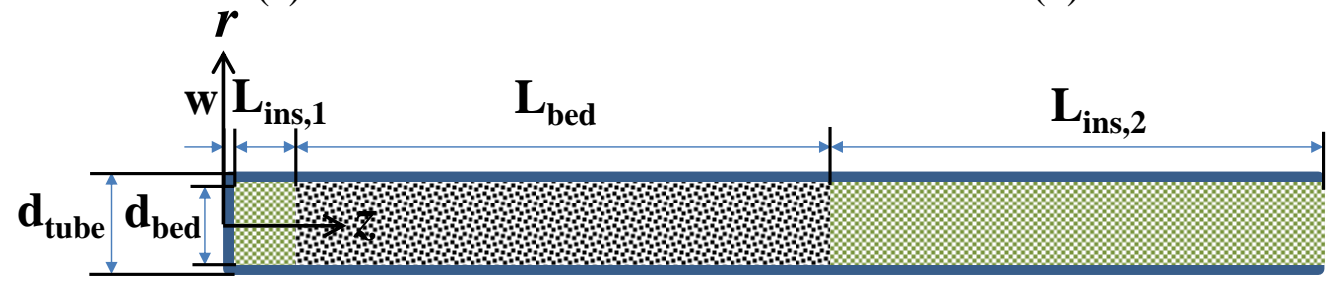

(c)

Fig. 2. Simplified computational domains in (a) the $r-z$ plane (the temperature evolutions at the locations 1-9 are shown in Fig. 10), (b) the $x$ - $y$ plane of the cavity-receiver module, and (c) the $r$ $z$ plane of one representative tube of the absorber-reactor module. The center tube is neglected.

\section{Radiative transfer in the cavity-receiver}

In the present solar thermochemical reactor as shown in Fig. 1, the cavity allows multiple reflections of the solar rays so that the behavior of the cavity closely resembles that of a black body. Due to multiple reflections inside the cavity, the apparent absorptivity of the cavity increases as compared to the actual absorptivity of the cavity material [26]. The reactants inside the tubular absorbers are indirectly heated by the solar flux. For lab-scale reactor prototypes, the UF HFSS with a peak flux of $5000 \mathrm{~kW} / \mathrm{m}^{2}$ is used as a radiation source. Radiative transfer modeling from the solar simulator to the aperture of the cavity receiver is performed using the VEGAS code [27]. A collision based Monte-Carlo ray tracing (MCRT) model is used to further 
trace the rays from the aperture until they get absorbed by the surfaces inside the cavity or escape the cavity through the aperture.

\subsection{Radiation from HFSS to reactor aperture - the VEGAS code}

The VEGAS code was developed by Petrasch [27] to simulate the radiative transfer from a solar simulator to a target object (the open aperture in this study). The UF HFSS consists of seven $6 \mathrm{~kW} \mathrm{Xe} \mathrm{arc} \mathrm{lamps.} \mathrm{The} \mathrm{required} \mathrm{aperture} \mathrm{diameter} \mathrm{for} \mathrm{a} 10 \mathrm{~kW}_{\text {th }}$ cavity receiver is calculated using the VEGAS code. The fraction of the incident radiation at the aperture from the solar simulator varying with the diameter of the aperture is shown in Fig. 3. As the size of the aperture increases, the fraction of incident radiation admitted into the cavity increases; however with increased aperture size, the radiation losses through the aperture also increase. As a part of the radiation is absorbed by the surfaces of the reflective mirrors, the incident power at the aperture never converges to 1 . Approximately $75 \%$ of the radiative power output from the solar simulator is incident at a $5 \mathrm{~cm}$ diameter aperture, which is the size in the present reactor configuration. Both the flux distribution and the directional information of the rays at the aperture are further used in the radiation modeling within the cavity-receiver.

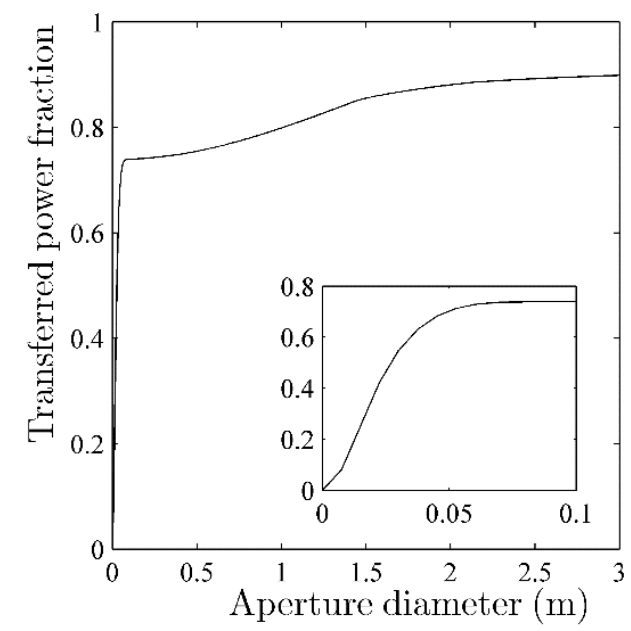

Fig. 3. Variations of the fraction of transferred power from the UF HFSS to the aperture with increase in the aperture diameter. 


\subsection{Radiation inside cavity-receiver}

A collision based MCRT model is developed to trace the rays from the aperture of the cavity until they are either absorbed by the surfaces of the 14 tubes or the inner surfaces of the cavity walls (including the inner front plate, the cylindrical insulation layer, and the back plate, see Fig. 1), or escape the cavity through the aperture. Temperature-dependent re-emission from all the surfaces inside the cavity is also taken into account with the heat transfer inside the absorbers and the cavity walls simulated. The generated rays due to surface re-emission will also be absorbed by other surfaces or escape the cavity through the aperture, and they are traced with the MCRT model as well. The net radiative flux at a given surface element is the difference between the absorbed and emitted fluxes [28]. The net flux distributions provide the necessary boundary conditions for the heat transfer modeling inside the absorbers and that in the insulation layers as presented in Section 4. The computed surface temperatures are then used to update the re-emission in the MCRT.

For ray tracing of the incident solar radiation, each ray is assumed to carry the same amount of power so that the incident power, $Q_{\text {ray,inc, }}$ carried by each ray at the aperture is given by

$$
Q_{\text {ray,inc }}=\frac{Q_{\text {input simulator }}}{N_{\text {ray, inc }}},
$$

The surfaces of the inner cavity and absorbers are assumed to be diffusely reflecting and emitting. Each surface is divided into a number of small elements of equal area and the surface temperature on each element is uniform. The direction of a diffusely reflected ray is given by the unit vector $\hat{\mathrm{s}}=[\sin \theta \cos \psi, \sin \theta \sin \psi, \cos \theta]^{\mathrm{T}}$, randomly determined by the polar angle, $\theta$, and the azimuthal angle, $\psi$, using 


$$
\theta=\sin ^{-1} \sqrt{\mathfrak{R}_{\theta}}, \text { and } \psi=2 \pi \mathfrak{R}_{\psi},
$$

where $\mathfrak{R}_{\theta}$ and $\mathfrak{R}_{\psi}$ are random numbers from 0 to 1 . The heat flux due to incident radiation on each of the surface elements is thus

$$
\begin{gathered}
q_{\mathrm{j}, \text { absorber }}^{\text {inc }}=n_{\mathrm{j}, \text { absorber }} Q_{\text {ray,inc }} / A_{\mathrm{j}, \text { absorber }}, \\
q_{\mathrm{j}, \text { cavity }}^{\text {inc }}=n_{\mathrm{j}, \text { cavity }} Q_{\text {ray,inc }} / A_{\mathrm{j}, \text { cavity }},
\end{gathered}
$$

where $n_{\mathrm{j}}$ is the number of rays incident on the element of area $A_{\mathrm{j}}$ for both the absorber surfaces and the cavity walls. It should be noted that the incident heat flux distribution $q_{\mathrm{j}}^{\text {inc }}$ is independent of the surface temperatures, and it is determined by the distribution of the input solar flux at the aperture and the geometry of the cavity-reactor. Thus the MCRT for determining $q_{\mathrm{j}}^{\text {inc }}$ is conducted only once.

The numbers of rays generated for modeling re-emission on the surfaces are given by

$$
N_{\mathrm{i}, \text { cavity }}=\frac{\varepsilon \sigma T_{\mathrm{i}, \text { cavity }}^{4} A_{\mathrm{i}, \text { cavity }}}{Q_{\text {cavity }}} N_{\text {ray,emi }}, \text { and } N_{\mathrm{i}, \text { absorber }}=\frac{\varepsilon \sigma T_{\mathrm{i}, \text { absorber }}^{4} A_{\mathrm{i}, \text { absorber }}}{Q_{\text {absorber }}} N_{\text {ray,emi }} \text {, }
$$

where $T_{\mathrm{i}}$ is the surface temperature on the $i$-th element, $A_{\mathrm{i}}$ is the elemental area, $N_{\text {ray,emi }}$ is the total number of arrays generated on the cavity wall or the absorber surface. And the total power on the cavity wall and absorber surfaces are

$$
Q_{\text {cavity }}=\sum_{i=1}^{N} \varepsilon \sigma T_{\mathrm{i}, \text { cavity }}^{4} A_{\mathrm{i}, \text { cavity }}, \text { and } Q_{\text {absorber }}=\sum_{i=1}^{N} \varepsilon \sigma T_{\mathrm{i}, \text { absorber }}^{4} A_{\mathrm{i}, \text { absorber }} .
$$

A portion of the generated rays, $N_{\mathrm{i}, \text { cavity }}$, for re-emission from the element $A_{\mathrm{i}, \text { cavity }}$ on the cavity wall escape the cavity through the aperture; the rest are absorbed by either element $A_{\mathrm{j}, \text { absorber }}$ on the absorber surfaces $\left(a_{\mathrm{i}, \mathrm{j}}\right)$, or $A_{\mathrm{j}, \text { cavity }}$ on the cavity walls $\left(b_{\mathrm{i}, \mathrm{j}}\right)$. The respective fractions are

$$
a_{\mathrm{i}, \mathrm{j}}=\frac{N(\text { absorber })_{\mathrm{i}, \mathrm{j}}}{N_{\mathrm{i}, \text { cavity }}}, b_{\mathrm{i}, \mathrm{j}}=\frac{N(\text { cavity })_{\mathrm{i}, \mathrm{j}}}{N_{\mathrm{i}, \text { cavity }}}
$$


Similarly, the fractions of the emissive rays, $N_{\mathrm{i}}$ absorber, generated on the element $A_{\mathrm{i}, \text { absorber }}$ of the absorber surface that are absorbed by element $A_{\mathrm{j}, \text { absorber }}$ on the absorber surfaces $\left(c_{\mathrm{i}, \mathrm{j}}\right)$, or $A_{\mathrm{j}, \text { cavity }}$ on the cavity walls $\left(d_{\mathrm{i}, \mathrm{j}}\right)$ are

$$
c_{\mathrm{i}, \mathrm{j}}=\frac{N(\text { absorber })_{\mathrm{i}, \mathrm{j}}}{N_{\mathrm{i}, \text { absorber }}}, d_{\mathrm{i}, \mathrm{j}}=\frac{N(\text { cavity })_{\mathrm{i}, \mathrm{j}}}{N_{\mathrm{i}, \text { absorber }}} .
$$

From Eqs. (9) and (10), the heat flux distributions due to re-emission and absorption are

$$
\begin{gathered}
q_{\mathrm{j}, \text { absorber }}^{\mathrm{emi}}=\varepsilon \sigma T_{\mathrm{j}, \text { absorber }}^{4}-\sum_{i}\left(a_{\mathrm{i}, \mathrm{j}} \mathrm{Q}_{\mathrm{i}, \text { cavity }}+c_{\mathrm{i}, \mathrm{j}} \mathrm{Q}_{\mathrm{i}, \text { absorber }}\right) / A_{\mathrm{j}, \text { absorber }}, \\
q_{\mathrm{j}, \text { cavity }}^{\text {emi }}=\varepsilon \sigma T_{\mathrm{j}, \text { cavity }}^{4}-\sum_{i}\left(b_{\mathrm{i}, \mathrm{j}} \mathrm{Q}_{\mathrm{i}, \text { cavity }}+d_{\mathrm{i}, \mathrm{j}} \mathrm{Q}_{\mathrm{i}, \text { absorber }}\right) / A_{\mathrm{j}, \text { cavity }} .
\end{gathered}
$$

The combination of Eqs. $(5,6)$ and $(11,12)$ give the net heat flux on the surface elements

$$
\begin{gathered}
q_{\mathrm{j}, \text { absorber }}^{\text {net }}=q_{\mathrm{j}, \text { absorber }}^{\text {inc }}-q_{\mathrm{j}, \text { absorber }}^{\mathrm{emi}}, \\
q_{\mathrm{j} \text {,cavity }}^{\text {net }}=q_{\mathrm{j}, \text { cavity }}^{\text {inc }}-q_{\mathrm{j}, \text { cavity }}^{\text {emi }} .
\end{gathered}
$$

For sufficient number of $N_{\text {ray,emi }}$ used $\left(N_{\text {ray,emi }}=10^{6}\right.$ in present simulations), the heat flux obtained from Eqs. (13) and (14) would give the same asymptotic results as that from the radiosity enclosure approach.

To further reduce the computational time of the MCRT for the re-emission, all the fractions $a_{\mathrm{i}, \mathrm{j}}, b_{\mathrm{i}, \mathrm{j}}, c_{\mathrm{i}, \mathrm{j}}$ and $d_{\mathrm{i}, \mathrm{j}}$ (similar to view factors) in Eqs. (9) and (10) are saved before the coupled time-marching. They are directly used to calculate the heat flux values once the surface temperatures are obtained from the heat transfer simulation inside the absorbers and the cavity walls, which will be simulated with the lattice Boltzmann (LB) model introduced in the following section.

\section{Heat transfer in the absorber-reactors and the cavity insulation layers}


Heat transfer within the porous bed of reactive material follows typical porous media thermal transport, which has been extensively studied in the literature. In addition to heat conduction and convection in the solid and fluid phases, radiative transfer is significant at high temperatures. With chemical reactions involved, the heat absorbed/released during the endothermic/exothermic reactions also contributes to the energy transport in the porous structure. A transient numerical model is required to simulate the multi-mechanism heat transfer coupled with chemical reactions in the absorber-reactors. Notably, to have realistic thermal boundary conditions for the porous bed, a full-scale tubular absorber is modeled, including the tube material, packed ceria bed, and the insulation blocks in the reactor absorber (see Fig. 2c). Moreover, realizing that the identically packed 14 tubes are equally distributed in the cavity and exposed to the semi-axisymmetric incident solar flux, the heat transfer in each of the 14 tubes are

assumed to be the same. Thus only one representative tube (Absorber 1 in Fig. 2b) is simulated and identical surface temperature distributions are assumed for the others when calculating the radiative emission from all tubes in the succeeding MCRT step.

\subsection{The governing equations}

The energy conservation equation for a porous bed can be written as a general convection-diffusion equation with source terms [29]

$$
\left[\varepsilon\left(\rho c_{p}\right)_{f}+(1-\varepsilon)\left(\rho c_{p}\right)_{s}\right] \frac{\partial T}{\partial t}+\varepsilon\left(\rho c_{p}\right)_{f} \mathbf{u} \cdot \nabla T=\nabla \cdot\left(k_{\mathrm{cond}} \nabla T\right)+\nabla \cdot \mathbf{q}_{\mathrm{rad}}+q_{\mathrm{chem}}^{\prime \prime \prime},
$$

where the subscripts $f$ and $s$ denote the fluid (gas) and solid phases, respectively, $\varepsilon$ is the porosity, $\rho$ is the material density, $c_{p}$ is the specific heat, $t$ is the time, $T$ is the temperature, $\mathbf{u}$ is the fluid velocity, $k_{\text {cond }}$ is the effective thermal conductivity of the porous structure, $\mathbf{q}_{\mathrm{rad}}$ is the radiation heat flux, and $q_{\mathrm{chem}}^{\prime \prime \prime}$ is the rate of volumetric heat sink/source due to the endothermic/exothermic 
reaction. It should be noted that Eq. (15) is the energy equation after volume averaging with the local thermal equilibrium assumption.

For optically thick and isotropic medium, the Rosseland diffusion approximation is considered valid for radiation transport [7, 19, 28], and Eq. (15) becomes

$$
\left(\rho c_{p}\right)_{\text {bed }} \frac{\partial T}{\partial t}+\varepsilon\left(\rho c_{p}\right)_{f} \mathbf{u} \cdot \nabla T=\nabla \cdot\left[k_{\mathrm{eff}} \nabla T\right]+q_{\mathrm{chem}}^{\prime \prime \prime}
$$

where $\left(\rho c_{p}\right)_{\text {bed }}=\varepsilon\left(\rho c_{p}\right)_{f}+(1-\varepsilon)\left(\rho c_{p}\right)_{s}$ and $k_{\text {eff }}=k_{\text {cond }}+\frac{16 n^{2} \sigma T^{3}}{3 \beta_{R}}$ with $n$ the refractive index of the medium, $\sigma$ the Stefan-Boltzmann constant, and $\beta_{R}$ the Rosseland-mean extinction coefficient of the bed structure. The temperature dependent chemical reaction sink/source terms is

$$
q_{\text {chem }}^{\prime \prime \prime}=r^{\prime \prime \prime} \Delta H_{r \times n},
$$

where $r^{\prime \prime \prime}$ is the volumetric reaction rate and $\Delta H_{r \times n}$ is the enthalpy change of the reaction. The reaction rate $r^{\prime \prime \prime}$ is related to the material kinetics as well as the local temperature and pressure conditions and can be predicted with specific kinetic models.

In this work, the reactive material considered is comprised of ceria particles that have been heat treated and sieved in the size range of 700-2000 $\mu \mathrm{m}$. Only the thermal reduction step is simulated for which the intrinsic reduction kinetics of ceria is much faster than the change of equilibrium status; thus the thermal equilibrium is assumed at all times, and the reaction rate is determined by the temperature and the partial pressure of $\mathrm{O}_{2}$ [23]. For ceria participating in a nonstoichiometric reaction with oxygen:

$$
\mathrm{CeO}_{2} \rightarrow \mathrm{CeO}_{2-\delta}+\frac{\delta}{2} \mathrm{O}_{2}
$$


the extent of reduction, $\delta$, achieved at thermodynamic equilibrium in the reduction step can be expressed as a function of $P_{\mathrm{O} 2}$ and $T$ [30]

$$
\frac{\delta}{0.35-\delta}=8700 P_{\mathrm{o}_{2}}^{-0.217} \exp \left(\frac{-195.6 \mathrm{~kJ} \mathrm{~mol}}{R T}\right)
$$

where $P_{\mathrm{O} 2}$ has a unit of bar. Denoting $M_{\mathrm{CeO}_{2}}$ as the molar mass of ceria, the reaction rate $r^{\prime \prime \prime}$ can then be written as

$$
r^{\prime \prime \prime}=\frac{\rho_{\text {bed }}}{2 M_{\mathrm{CeO}_{2}}} \frac{\partial \delta}{\partial t}
$$

Realizing that the extent of reduction can be explicitly described by the local temperature and $\mathrm{O}_{2}$ partial pressure as in Eq. (19), the sink term can be incorporated with the transient term to improve numerical stability. Substitution of Eqs. $(17,19,20)$ into the last term in Eq. (16) gives

$$
\left(\rho c_{p}\right)_{\text {bed }} \frac{\partial T}{\partial t}+\varepsilon\left(\rho c_{p}\right)_{f} \mathbf{u} \cdot \nabla T=\nabla \cdot\left[k_{\text {eff }} \nabla T\right]+\frac{\rho_{\mathrm{bed}}}{2 M_{\mathrm{CeO}_{2}}}\left(\frac{\partial \delta}{\partial T} \frac{\partial T}{\partial t}\right) \Delta H_{r \times n}
$$

And the rearrangement of Eq. (21) yields

$$
\frac{\partial T}{\partial t}+\varepsilon \frac{\left(\rho c_{p}\right)_{f}}{\left(\rho c_{p}\right)_{\mathrm{imp}}} \mathbf{u} \cdot \nabla T=\frac{1}{\left(\rho c_{p}\right)_{\mathrm{imp}}} \nabla \cdot\left[k_{\mathrm{eff}} \nabla T\right]
$$

where $\left(\rho c_{p}\right)_{\text {imp }}=\left(\rho c_{p}\right)_{\text {bed }}+\frac{\rho_{\text {bed }}}{2 M_{\mathrm{CeO}_{2}}} \frac{\partial \delta}{\partial T} \Delta H_{r \times n}$ and $\frac{\partial \delta}{\partial T}$ can be analytically determined from Eq. (19).

\subsection{Boundary conditions}

The main thermal boundary conditions for modeling the solar reactor include:

(1) Neumann conditions with net heat flux distributions on the absorber outer surface $(r=$ $R_{a}$ ) and the inner cavity walls; taking the tube surface as an example, 


$$
q_{\text {tube }}^{\text {net }}=-\left.k_{\text {tube }} \frac{\partial T}{\partial r}\right|_{r=R_{a}},
$$

where $q_{\text {tube }}^{\text {net }}$ is obtained from Eq. (13) in the MCRT radiation model in Section 3.

(2) Natural convection and radiative emission conditions on the surfaces exposed to ambient, such as the end of the tubes and the outer surface of the insulation layers

$$
-\left.k_{\mathrm{s}} \frac{\partial T}{\partial n}\right|_{w}=h\left(T_{w}-T_{\mathrm{amb}}\right)+\varepsilon_{\mathrm{s}} \sigma\left(T_{w}^{4}-T_{\mathrm{amb}}^{4}\right)
$$

where $k_{\mathrm{s}}$ is the thermal conductivity of the solid surface, $h$ is the heat transfer coefficient due to natural convection, $T_{w}$ is the surface temperature, $T_{\mathrm{amb}}$ is the ambient temperature, and $\varepsilon_{\mathrm{s}}$ is the surface emissivity.

(3) Conjugate heat transfer conditions at the interface of two materials of different thermal properties: such as the tube inner surface (interface between tube and porous bed), the interfaces between the porous bed and insulation blanket within the tubes, and the interfaces between the insulation layers. Taking the cylindrical interface between the tube and the reactive bed as an example, when the thermal resistance is neglected, the standard conjugate conditions including the continuity of temperature and normal heat flux at the interface are

$$
\begin{gathered}
T_{\text {tube,int }}=T_{\text {bed,int }}, \\
\left.k_{\text {tube }} \frac{\partial T_{\text {tube }}}{\partial r}\right|_{\text {int }}=\left.k_{\text {bed }} \frac{\partial T_{\text {bed }}}{\partial r}\right|_{\text {int }} .
\end{gathered}
$$

\subsection{Lattice Boltzmann model for the convection-diffusion equation}

The scalar convection-diffusion equation (CDE) for temperature in Eq. (15) can be numerically solved using traditional finite-difference or finite-volume methods. In this work, we use an alternative, the lattice Boltzmann equation (LBE) method, for Eq. (15). The LBE method has become an attractive alternative numerical method for heat and mass transfer modeling [31- 
36] for its inherent benefits including: (i) simplicity and explicitness of the algorithm, (ii) convenience in handling irregular boundaries and interfaces, and (iii) compatibility with parallel computation.

In LB modeling for heat transfer, a temperature distribution function $g(\mathbf{x}, \boldsymbol{\xi}, t)$ is defined in the Cartesian coordinate system, where $\mathbf{x}$ is the spatial position vector, $\boldsymbol{\xi}$ is the particle velocity vector in the phase space $(\mathbf{x}, \boldsymbol{\xi})$ and $t$ is the time. Its evolution is very efficiently computed following a standard collision-streaming process

collision step:

$$
\hat{g}_{\alpha}(\mathbf{x}, t)=g_{\alpha}(\mathbf{x}, t)-\left[\mathrm{M}^{-1} \mathrm{~S}\left(\mathbf{m}-\mathbf{m}^{\mathrm{eq}}\right)\right]_{\alpha}(\mathbf{x}, t)+\omega_{\alpha} G(\mathbf{x}, t) \delta t
$$

streaming step:

$$
g_{\alpha}\left(\mathbf{x}+\mathbf{e}_{\alpha} \delta t, t+\delta t\right)=\hat{g}_{\alpha}(\mathbf{x}, t)
$$

where $g_{\alpha}(\mathbf{x}, t) \equiv g\left(\mathbf{x}, \xi_{\alpha}, t\right)$ is the distribution along the discrete lattice vector $\mathbf{e}_{\alpha}$ direction, $\hat{g}_{\alpha}$ represents the post-collision state, $\mathrm{M}$ is a matrix to transform the distribution functions $\mathbf{g}$ to their moments $\mathbf{m}$ by $\mathbf{m}=\mathrm{Mg}, \mathrm{S}$ is a matrix of relaxation coefficients, the equilibrium moments are explicitly defined as $\mathbf{m}^{(\mathrm{eq})}=(0, u \phi, v \phi, w \phi, a \phi, 0,0)^{\mathrm{T}}$ with $u, v$, and $w$ being the macroscopic velocity components in the Cartesian coordinates, $\phi$ being the macroscopic scalar variable (temperature $T$ in this work), and $a$ being a constant, $G$ is the general source term in the convection-diffusion equation (see Eq. (27) below), and $\delta t$ is the time step. The collision step is completely local, and the streaming step is very simple and requires minimal computational resource.

When performing an asymptotic analysis [31], it can be shown that the macroscopic convection-diffusion equation (CDE) recovered from Eqs. $(26 a, b)$ is 


$$
\frac{\partial \phi}{\partial t}+\nabla \cdot \mathbf{u} \phi=\nabla \cdot(D \nabla \phi)+G
$$

when the scalar $\phi$ is obtained from the moment of the distribution functions

$$
\phi(\mathbf{x}, t)=\sum_{\alpha} g_{\alpha}(\mathbf{x}, t)
$$

and the diffusion coefficient $D$ is related to the relaxation time coefficient $\tau_{D}$ in $S$ as

$$
D=\left(\tau_{D}-0.5\right) / 4 \text { in } 3 \mathrm{D} \text {, and } D=\left(\tau_{D}-0.5\right) / 3 \text { in } 2 \mathrm{D}
$$

The D3Q7 (DnQm denotes $m$ discrete velocities in $n$ dimensions) LB model in 3D and D2Q5 model in 2D cases are used in this work. For more details on the LBE method and its boundary and interface condition implementations please refer to $[31,32,35]$.

Heat conduction in the cavity insulation layers, including the three cylindrical layers, the circular front and back plates, and the insulation blanket (see Fig. 2 (b)), is also modeled with the LB method by setting the macroscopic velocity to zero.

\subsection{Scaling between the physical and LB unit systems}

The physical unit and the LB unit systems are connected by the same dimensionless characteristic variables. In the present model, the following two scale factors are used to transfer the variables between the two unit systems:

$$
\begin{aligned}
& L_{x}=R_{\mathrm{phys}} / R_{\mathrm{LBE}}, \text { in the length scale, and } \\
& \Gamma_{t}=t_{\mathrm{phys}} /\left(N_{t} \delta t\right)_{\mathrm{LBE}}, \text { in the time scale, }
\end{aligned}
$$

where $R_{\text {phys }}$ and $R_{\mathrm{LBE}}$ are the radii in the respective physical and LBE unit systems, $t_{\text {phys }}$ is the physical reference time and $N_{t}$ is the number of time steps in LB unit with $\delta t=1$.

With the scale factors defined in Eqs. $(30 \mathrm{a}, \mathrm{b})$, the diffusion coefficient in the LB model (see Eq. (27)) for Eq. (22) becomes 


$$
D_{\mathrm{LBE}}=\alpha_{\mathrm{phys}} \frac{\Gamma_{t}}{L_{x}^{2}}=\frac{k_{\mathrm{eff}}}{\left(\rho c_{p}\right)_{\mathrm{imp}}} \frac{\Gamma_{t}}{L_{x}^{2}},
$$

and thus the Neumann flux boundary condition for Eq. (23) in the LB unit is

$$
\begin{aligned}
& \left(\Phi_{n}\right)_{\mathrm{LBE}}=-\left(\left.D_{\text {tube }} \frac{\partial \phi}{\partial r}\right|_{r=R_{a}}\right)_{\mathrm{LBE}}=-\left.\left(D_{\text {tube }}\right)_{\mathrm{LBE}} \frac{\left(R_{\text {tube }}\right)_{\text {phys }}}{\left(R_{\text {tube }}\right)_{\mathrm{LBE}}} \frac{\partial T}{\Delta T \partial r}\right|_{r=R_{a}, \text { phys }} \\
& =-\left.\left(\frac{k}{\rho c_{p}}\right)_{\text {tube,phys }} \frac{\Gamma_{t}}{L_{x}^{2}} \frac{\left(R_{\text {tube }}\right)_{\text {phys }}}{\left(R_{\text {tube }}\right)_{\mathrm{LBE}}} \frac{\partial T}{\Delta T \partial r}\right|_{r=R_{a}, \text { phys }}=\frac{\Gamma_{t}}{\Delta T L_{x}} \frac{q_{\text {tube,phys }}^{\text {net }}}{\left(\rho c_{p}\right)_{\text {tube,phys }}},
\end{aligned}
$$

where $\Delta T$ is a reference temperature introduced to normalize the physical temperature, i.e., $\phi=T / \Delta T$.

In LB modeling, the positivity of the diffusion coefficient requires $\tau_{D}>0.5$. Smaller $\tau_{D}$ values indicate smaller time steps, and thus more iterations are required in simulations; on the other hand, the numerical error increases with $\tau_{D}$ at large $\tau_{D}$ values. Thus the scaling factors $L_{x}$ and $\Gamma_{t}$ should be adjusted to constrain $\tau_{D}$ in a reasonable range, e.g, $0.501<\tau_{D}<2.0[31-36]$. Two numerical tests will be presented in the beginning of Section 5 to validate the scaling strategy in the LB modeling.

\section{Results and discussion}

\subsection{Numerical validation for the rescaling technique in the $\mathrm{LB}$ model}

The rescaling technique for the diffusion coefficient in the LBE method is validated in this section with two numerical examples for which analytical solutions are available. The two problems were also studied in [32] to verify the boundary schemes.

\subsubsection{Transient heat conduction in an inclined semi-infinite solid}

This example considers the transient heat conduction into an inclined semi-infinite solid when a constant heat flux is supplied at the end as shown in Fig. 4. The initial temperature is 
zero in the solid, and a constant heat flux condition is imposed as (assuming $\rho c_{p}=1$ ) $q_{w}=-\left.D \frac{\partial \phi}{\partial n}\right|_{l=0}=\frac{\sqrt{D \pi}}{2}$. The transient temperature along the solid is [32]

$$
\phi_{\mathrm{ex}}(D, t, l)=t^{1 / 2}\left[e^{-l^{2} /(4 D t)}-\frac{l \sqrt{\pi}}{2 \sqrt{D t}} \operatorname{erfc}\left(\frac{l}{2 \sqrt{D t}}\right)\right]
$$

where $l$ is the distance in the normal direction and "erfc" is the complementary error function. The temperature on the wall is thus $f(t)=\phi(t, l=0)=t^{1 / 2}$.

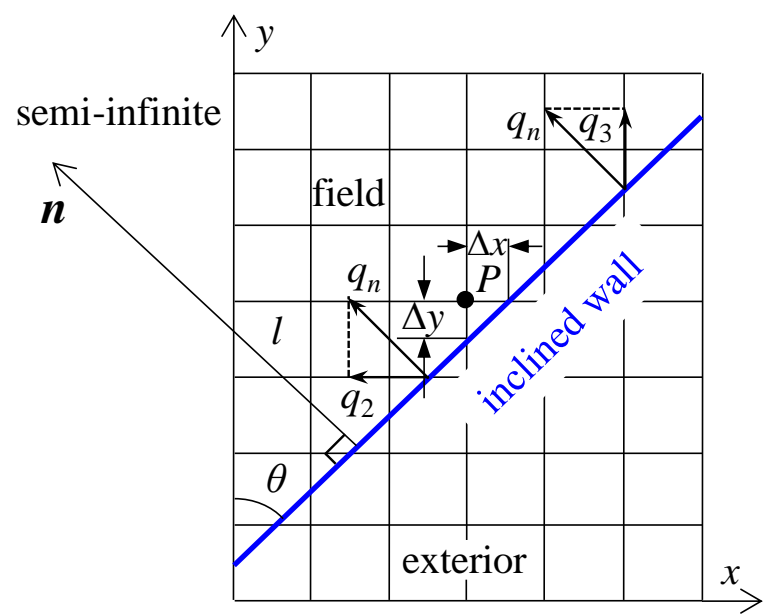

Fig. 4. Layout of the lattice around the inclined semi-infinite solid.

With no temperature variation along the tangential direction, the boundary heat fluxes in the discrete velocity directions are equal to the projections of the normal heat flux in those directions. Thus the decoupled Neumann condition treatment proposed in [32] is directly implemented.

To examine the rescaling of the diffusion coefficient, we consider the "physical" solution at $D=5 / 6$ and $t=10 \delta t$, for which the corresponding relaxation coefficient is $\tau_{D}=3.0$ according to Eq. (29). Direct use of this high $\tau_{D}$ value would lead to large numerical errors in the LB simulations (see Fig. 5). To mitigate large numerical error from the use of large $\tau_{D}$, we apply the rescaling strategy in Eqs. $(30,31)$ with $D^{\prime}=D / \lambda$ and $t^{\prime}=\lambda t$. i.e., $L_{x}=1$ and $\Gamma_{t}=1 / \lambda$. 
It should be noted that the boundary heat flux should also be rescaled as $q_{w}^{\prime}=-\left.D^{\prime} \frac{\partial \phi}{\partial n}\right|_{l=0}=\frac{\sqrt{D \pi}}{2 \lambda}$. Fig. 5 (a) compares the LBE results $\phi_{\mathrm{LBE}}\left(D^{\prime}=5 /(6 \lambda), t^{\prime}=10 \lambda \delta t, l\right)$ at various $\lambda$ values with the analytical solution $\phi_{\mathrm{ex}}(D=5 / 6, t=10 \delta t, l)$ for the temperature profiles along the vertical line going through point $P$ in Fig. 4 at an inclination angle $\theta=\pi / 4$. Note that the distance from the lattice nodes to the solid wall has been converted to that along the normal direction. The absolute errors of the numerical solutions, $e=\phi_{\mathrm{LBE}}-\phi_{\mathrm{ex}}$, are also shown in Fig. 5 (b).

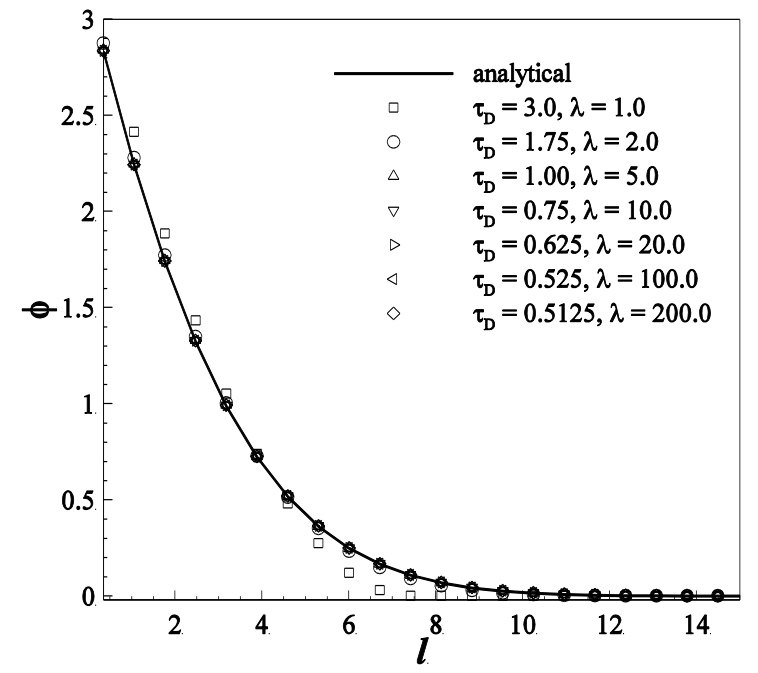

(a)

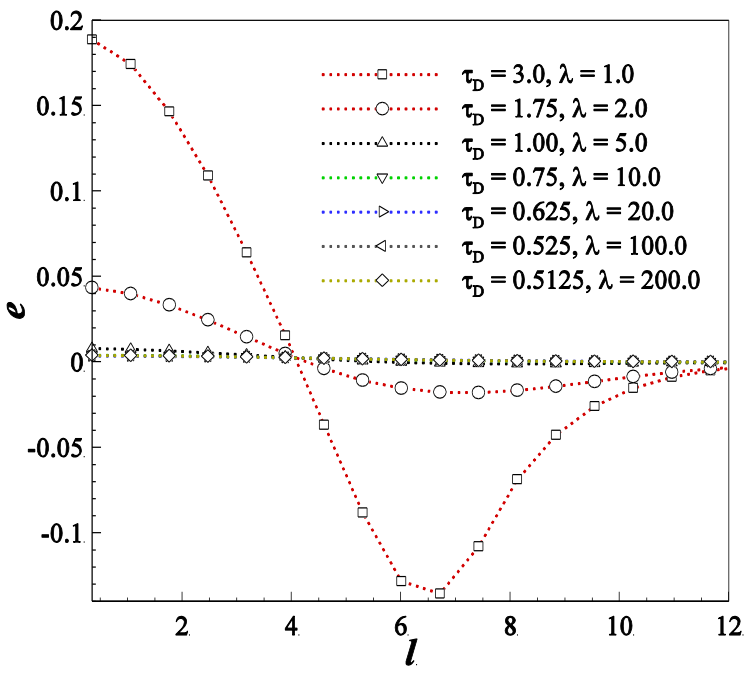

(b)

Fig. 5. (a) Temperature profiles along the vertical line going through $P$ in Fig. 4, and (b) absolute errors of the LBE results presented in (a).

The LBE results with large relaxation coefficient $\tau_{D}=3.0$ have quite noticeable errors in Fig. 5 $(\mathrm{a}, \mathrm{b})$. When the diffusion coefficient is rescaled down to smaller values, the numerical errors are reduced and better agreement between the LBE results and the analytical solution is achieved. It is also observed in Fig. $5(\mathrm{a}, \mathrm{b})$ that very close numerical solutions are obtained for $\tau_{D} \leq 1.0$

\subsubsection{Transient heat conduction inside a circle}


Transient heat conduction inside a circle of radius $r_{0}$ is considered in this example where a Dirichlet condition $\phi\left(t, r=r_{0}\right)=f(t)=\sin (\omega t)$ is applied, with $\omega$ being the frequency of the imposed temperature variation on the boundary. This transient problem is characterized by the Stokes number $S t=\sqrt{\frac{r_{0}^{2} \omega}{2 \pi D}}$. Assuming the temperature is uniform in the azimuthal direction, the analytical solution for this $2 \mathrm{D}$ problem is [32]

$$
\begin{aligned}
\phi_{\mathrm{ex}}(r, t)=f(t)-\frac{2}{r_{0}} \sum_{n=1}^{\infty} \frac{J_{0}\left(\beta_{n} r\right)}{\beta_{n} J_{1}\left(\beta_{n} r_{0}\right)}\left[f(0) e^{-D \beta_{n}^{2} t}+\int_{0}^{t} e^{-D \beta_{n}^{2}(t-\tau)} d f(\tau)\right] \\
=\sin (\omega t)-\frac{2}{r_{0}} \sum_{n=1}^{\infty} \frac{\omega J_{0}\left(\beta_{n} r\right)}{\beta_{n} J_{1}\left(\beta_{n} r_{0}\right)}\left[\frac{D \beta_{n}^{2} \cos (\omega t)+\omega \sin (\omega t)-D \beta_{n}^{2} e^{-D \beta_{n}^{2} t}}{\left(D \beta_{n}^{2}\right)^{2}+\omega^{2}}\right],
\end{aligned}
$$

where $J_{i}(\beta r)(i=0,1)$ is the solution to the Bessel's function of the first kind of order $i$, and $\beta_{n}$ is determined from the roots of $J_{0}\left(\beta_{n} r_{0}\right)=0$ for a given $r_{0}$.

As shown in Fig. 6, the lattice fractions $\Delta x$ and $\Delta y$ for each lattice link intersected by the curved boundary are calculated to implement the Dirichlet treatment in [32].

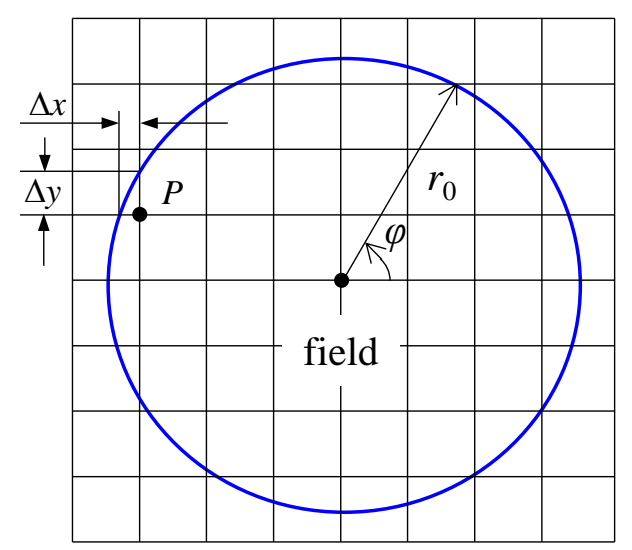

Fig. 6. Schematic layout of the lattice around a circle.

Again, the solution at $D=5 / 6$ (corresponding to $\tau_{D}=3.0$ ) and $t=10 \delta t$ is considered. Fig.

7 (a) compares the LBE results $\phi_{\mathrm{LBE}}\left(D^{\prime}=5 /(6 \lambda), t^{\prime}=10 \lambda \delta t\right)$ in the radial direction after the 
rescaling with the analytical solution $\phi_{\mathrm{ex}}(D=5 / 6, t=10 \delta t)$ at $S t=1$. The absolute errors of numerical results with the analytical solution are also given in Fig. 7 (b).

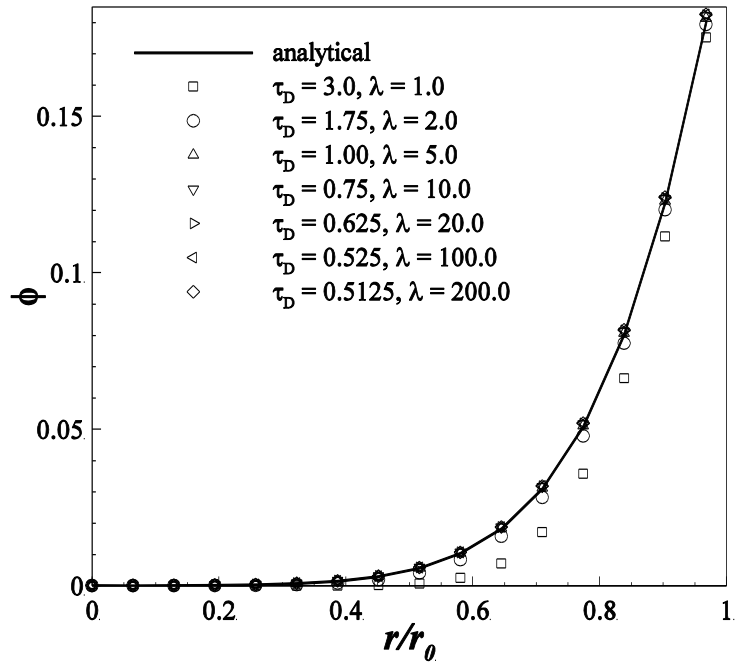

(a)

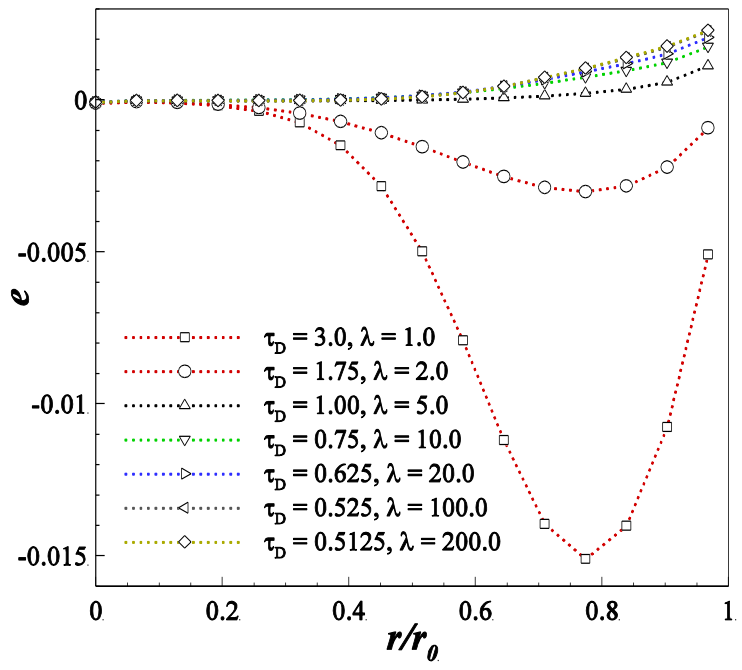

(b)

Fig. 7. (a) Temperature distributions in the radial direction, and (b) absolute errors of the LBE results presented in (a).

Similar to the results in Fig. 5, significant deviations and therefore large numerical errors are observed in Figs. $7(\mathrm{a}, \mathrm{b})$, respectively, with the direct use of $\tau_{D}=3.0$. Better numerical accuracy is obtained when the diffusion coefficient is rescaled down to a proper range. It is thus concluded that the presently proposed rescaling technique can be applied to simulate highdiffusivity problems to reduce numerical errors.

\subsection{Simulation results for the UF $10 \mathrm{~kW}$ solar reactor}

For the present simulation, the MCRT radiative transfer model for the cavity-receiver in Section 3 is coupled with the LB heat transfer model in Section 4 for the absorber-reactor and the insulation layers covering the cavity. This paper is focused on the preheating process and the first thermal reduction step. With thermal reduction more favorable under lower oxygen partial pressure, the vacuum concept is used for the reduction step [37] so that the convective heat transfer due to gas flow is negligible compared to the radiation and conduction in the bed. The 
convection term in Eq. (16) is thus neglected during the reduction step. Note that a stoichiometric ratio of $n_{\mathrm{H}_{2}}: n_{\mathrm{O}_{2}}=2: 1$ is assumed when predicting the fuel production based on the computed $\mathrm{O}_{2}$ production during the reduction step.

The initial condition is $T_{0}=298 \mathrm{~K}$ at $t=0$ for each component. During each time step, the thermophysical properties are considered constant, and the values from the previous time step are used. Since the time step in the thermal LB method is on the diffusion scale, intrinsically very small time step is implied. Thus this first-order accuracy approach is appropriate. With the incident flux distribution at the aperture from the solar simulator prescribed, the radiative transfer analysis in the cavity-receiver (taking into account the radiative emission from all surfaces) gives the net flux distributions on the absorber and cavity wall surfaces. With those boundary conditions, heat transfer coupled with chemical reactions in the array of absorber-reactors and the conduction inside the cavity insulation layers are simulated. The surface temperatures are then updated for the radiative transfer during the next time step. It should be emphasized that the incident flux distributions on each of the 14 tubes are not identical from MCRT simulation due to slight imperfection of the light source from the lamps. However the distributions are very close to each other, thus the flux distributions are averaged over the surfaces of 14 absorber walls. Only one tubular absorber (Absorber 1 in Fig. 2b) is simulated in the LB model. The surface temperature of Absorber 1 is then applied to the surfaces of the other 13 tubes in the subsequent steps.

The computational procedure for the transient simulation is summarized below.

(i) The incident solar power $P_{\text {solar }}$ and the distribution of the rays (each ray carries an equal amount of energy) at the cavity aperture is obtained from the VEGAS ray tracing code [27]; 
(ii) The MCRT radiation model is applied to obtain the incident fluxes (temperatureindependent) on the absorber and inner cavity walls;

(iii) With initial condition $T_{0}$ or surface temperatures obtained at the previous time step $t=t_{n}$ during time-marching, the radiative re-emission from each surface is computed. Eqs. $(13,14)$ are then applied to obtain the net flux conditions on the absorber and inner cavity walls;

(iv) The conduction and radiation coupled with chemical reaction inside Absorber 1, and the conduction inside the cavity walls (front, back plates and cylindrical layers) are simulated with the LB model at $t_{n+1}=t_{n}+\Delta t$;

(v) Temperature distributions on the outer surface of Absorber 1 and inner surfaces of the cavity walls are computed so that the radiative re-emission from those surfaces (including those of Absorbers 2-14) at $t_{n+1}$ are updated;

(vi) Continue steps (iii) - (v) until a desired stopping criterion, e.g., the reaction time or objective nominal bed temperature, is reached.

The thermophysical properties of the various materials are given in Table 1, and the baseline input parameters for the reactor simulation are listed in Table 2 . With the selected length and time scale factors in Table 2, the relaxation coefficients in the LB modeling for heat transfer in the different materials in Table 1 satisfy $0.54<\tau_{D}<1.73$ in the absorbers and $0.51<\tau_{D}<0.79$ in the cavity wall and insulation layers. As demonstrated in Figs. 5 and 7 in Section 5.1, the simulation results with such $\tau_{D}$ values are expected to have good numerical accuracy.

Figure 8 shows the variations of the spatially averaged bed temperature, $T_{\text {bed }}$, and its rate with time in Absorber 1 during the heating process and the first reduction step. The change of the solar power is also included in Fig. 8. During the first 50 min, a constant solar power $P_{\text {solar }}=10$ $\mathrm{kW}$ is supplied and the maximum $T_{\text {bed }}$ reaches $1570{ }^{\circ} \mathrm{C}$. The maximum ramp rate of $51{ }^{\circ} \mathrm{C} \cdot \mathrm{min}^{-1}$ 
is achieved at $t=6.5 \mathrm{~min}$; after that, the rate decreases and drops to $14{ }^{\circ} \mathrm{C} \cdot \mathrm{min}^{-1}$ at $t=50 \mathrm{~min}$.

The solar simulator lamps are turned off at $50 \mathrm{~min}$ and $P_{\text {solar }}$ becomes zero at $t>50 \mathrm{~min}$. A shutter is applied to cover the aperture and reduce the heat loss from the reactor (see Fig. 11 (d)). The simulation is continued under the reduced heating for another $5 \mathrm{~min}$ as shown in Fig. 8. A maximum cooling rate of $-25.8^{\circ} \mathrm{C} \cdot \mathrm{min}^{-1}$ is noticed and $T_{\text {bed }}$ drops to $1462{ }^{\circ} \mathrm{C}$ at $t=55 \mathrm{~min}$.

Table 1. Thermophysical material properties for the different materials used in the solar reactor (see Figs. 1 and 2).

\begin{tabular}{|c|c|c|}
\hline \multicolumn{2}{|l|}{ Density, $\rho\left(\mathrm{kg} \cdot \mathrm{m}^{-3}\right)$} & Value $(298 \mathrm{~K} \leq T \leq 2000 \mathrm{~K})$ \\
\hline Ceria packed bed & $\rho_{\text {bed }}$ & 1716.4 \\
\hline Alumina tube [38] & $\rho_{\text {tube }}$ & 3950.0 \\
\hline $\begin{array}{l}\text { Insulation Material } 1 \\
\text { (Buster M-35) [39] }\end{array}$ & $\rho_{\text {ins }, 1}$ & 560.7 \\
\hline $\begin{array}{l}\text { Insulation Material } 2 \\
\text { (Buster M-15) [39] }\end{array}$ & $\rho_{\text {ins }, 2}$ & 240.3 \\
\hline $\begin{array}{l}\text { Insulation Material } 3 \\
\text { (Buster Blanket) [39] }\end{array}$ & $\rho_{\text {ins }, 3}$ & 150.0 \\
\hline $\begin{array}{l}\text { Insulation Material } 4 \\
\text { (Microporous insulation) [40] }\end{array}$ & $\rho_{\text {ins }, 4}$ & 230.0 \\
\hline \multicolumn{2}{|c|}{ Thermal conductivity, $k\left(\mathrm{~W} \cdot \mathrm{m}^{-1} \cdot \mathrm{K}^{-1}\right)$} & Value $(298 \mathrm{~K} \leq T \leq 2000 \mathrm{~K})$ \\
\hline Porous bed [41] & $k_{\text {cond }}$ & $k_{\text {cond }} / k_{f}=\left(k_{s} / k_{f}\right)^{0.280-0.757 \log \varepsilon-0.057 \log \left(k_{s} / k_{f}\right)}$ \\
\hline $\begin{array}{l}\text { Argon (ref. gas during } \\
\text { vacuum) }\end{array}$ & $k_{f}$ & $4.2 \times 10^{-3}+5.6 \times 10^{-5} T-2.6 \times 10^{-8} T^{2}+1.1 \times 10^{-11} T^{3}-1.6 \times 10^{-15} T^{4}$ \\
\hline Ceria [23] & $k_{s}$ & $\frac{17.8004-2.4028 \times 10^{-2} T+1.12032 \times 10^{-5} T^{2}-1.7 \times 10^{-9} T^{3}}{7.9799+4.83384 \times 10^{-3} T-9.3397 \times 10^{-6} T^{2}+2.8 \times 10^{-9} T^{3}}$ \\
\hline Alumina tube [38] & $k_{\text {tube }}$ & $5.5+34.5 e^{-3.3 \times 10^{-3}(T-273.15)}$ \\
\hline Insulation Material 1 [39] & $k_{\mathrm{ins}, 1}$ & $2.2024 \times 10^{-2}+1.3924 \times 10^{-4} T+5.3512 \times 10^{-9} T^{2}$ \\
\hline Insulation Material 2 [39] & $k_{\mathrm{ins}, 2}$ & $1.1685 \times 10^{-1}-1.7636 \times 10^{-4} T+1.5032 \times 10^{-7} T^{2}$ \\
\hline Insulation Material 3 [39] & $k_{\text {ins }, 3}$ & $\left\{\begin{array}{l}0.083, T \leq 800 \mathrm{~K} \\
-2.435 \times 10^{-1}+3.607 \times 10^{-4} T+1.25 \times 10^{-8} T^{2}, T>800 \mathrm{~K}\end{array}\right.$ \\
\hline Insulation Material 4 [40] & $k_{\text {ins }, 4}$ & $9.1640 \times 10^{-4}+9.0320 \times 10^{-5} T-1.1810 \times 10^{-7} T^{2}+6.1469 \times 10^{-11} T^{3}$ \\
\hline Heat capacity, $c_{p}\left(\mathrm{~J} \cdot \mathrm{kg}^{-1} \cdot \mathrm{K}^{-1}\right)$ & & Value $(298 \mathrm{~K} \leq T \leq 2000 \mathrm{~K})$ \\
\hline Porous bed [23] & $c_{p \text {,bed }}$ & $299.86957+2.69766 \times 10^{-1} T-1.271 \times 10^{-4} T^{2}$ \\
\hline Alumina tube $[38]$ & $c_{p, \text { tube }}$ & $1.04 \times 10^{3}+1.74 \times 10^{-1} T-2.80 \times 10^{7} / T^{2}$ \\
\hline Insulation Materials 1-3 [39] & $c_{p, \text { ins1-3 }}$ & $447.6996+1.5987 T-1.3797 \times 10^{-3} T^{2}+4.0 \times 10^{-7} T^{3}$ \\
\hline Insulation Material 4 [40] & $c_{p, \text { ins } 4}$ & $\begin{array}{r}800.0 \\
\end{array}$ \\
\hline
\end{tabular}


Table 2. Baseline input parameters used in solar reactor simulations.

\begin{tabular}{lcc}
\hline \multicolumn{1}{c}{ Parameter } & & Value \\
\hline Incident solar power at aperture $(\mathrm{kW})$ & $P_{\text {solar }}$ & 10 \\
Ambient temperature $(\mathrm{K})$ & $T_{0}$ & 298 \\
Bed mass per tube $(\mathrm{kg})$ & $m_{\text {bed }}$ & 0.700 \\
Porosity of reactive bed & $\varepsilon$ & 0.776 \\
Partial pressure of $\mathrm{O}_{2}(\mathrm{bar})$ & $P_{\mathrm{O} 2}$ & $1.32 \times 10^{-4}$ \\
Mean extinction coefficient $\left(\mathrm{m}^{-1}\right)$ & $\beta_{R}$ & $10^{3}$ \\
Aperture diameter $(\mathrm{cm})$ & $D_{\text {aper }}$ & 5.00 \\
Cavity inner diameter $(\mathrm{cm})$ & $D_{\text {cav }}$ & 30.48 \\
Cavity length $(\mathrm{cm})$ & $L_{\text {cav }}$ & 30.48 \\
Tube outer diameter $(\mathrm{cm})$ & $D_{\text {tube }}$ & 5.08 \\
Tube thickness $(\mathrm{cm})$ & $t_{\text {tube }}$ & 0.3175 \\
Tube length $(\mathrm{cm})$ & $L_{\text {tube }}$ & 60.96 \\
Reactive bed length $(\mathrm{cm})$ & $L_{\text {bed }}$ & 30.48 \\
Time scale factor for absorber-reactor $\left(\mathrm{sec} \cdot \delta_{t}^{-1}\right)$ & $\Gamma_{t_{-} \text {abs }}$ & $2.50 \times 10^{-2}$ \\
Length scale factor for absorber-reactor $\left(\mathrm{m} \cdot \delta_{x}^{-1}\right)$ & $L_{x_{-} \text {abs }}$ & $9.96 \times 10^{-4}$ \\
Time scale factor for cavity-receiver $\left(\mathrm{sec} \cdot \delta_{t}^{-1}\right)$ & $\Gamma_{t_{-} \text {cav }}$ & $2.00 \times 10^{-1}$ \\
Length scale factor for cavity-receiver $\left(\mathrm{m} \cdot \delta_{x}^{-1}\right)$ & $L_{x_{-} \text {cav }}$ & $2.94 \times 10^{-3}$ \\
\hline
\end{tabular}

Figures 9 and 10 show the temperature evolutions at some specific locations in the reactor, of which Fig. 9 includes the nodes along the centerline of the cylindrical bed $(r=0)$ with the axial coordinates $\zeta=\left(z-w-L_{\mathrm{ins}, 1}\right) / L_{\mathrm{bed}}=0,0.25,0.5,0.75$, and 1 (see Fig. 2(c) for notations), and Fig. 10 is for the nodes on the inner cavity walls and within the insulation layers (see points 1-9 in Fig. 2(a)). A similar temperature profile is noticed for all the results in Fig. 9. For $0.25 \leq \zeta \leq 0.75$ the temperature values are close to each other and the values at the bottom $(\zeta$ $=0)$ and top $(\zeta=1)$ of the bed are about $200{ }^{\circ} \mathrm{C}$ lower. In Fig. 10, the highest temperature $\left(T_{6}\right)$ is observed at the center of the inner surface of the back plate, and it also has the largest cooling rate when $P_{\text {solar }}$ becomes 0 at $t>50 \mathrm{~min}$. The profiles of $T_{1}-T_{6}$ indicate that the present solar reactor design is capable of maintaining an effective high-temperature cavity surface, while the much lower temperatures $T_{7}-T_{9}$ demonstrate that the hot cavity is well insulated. 


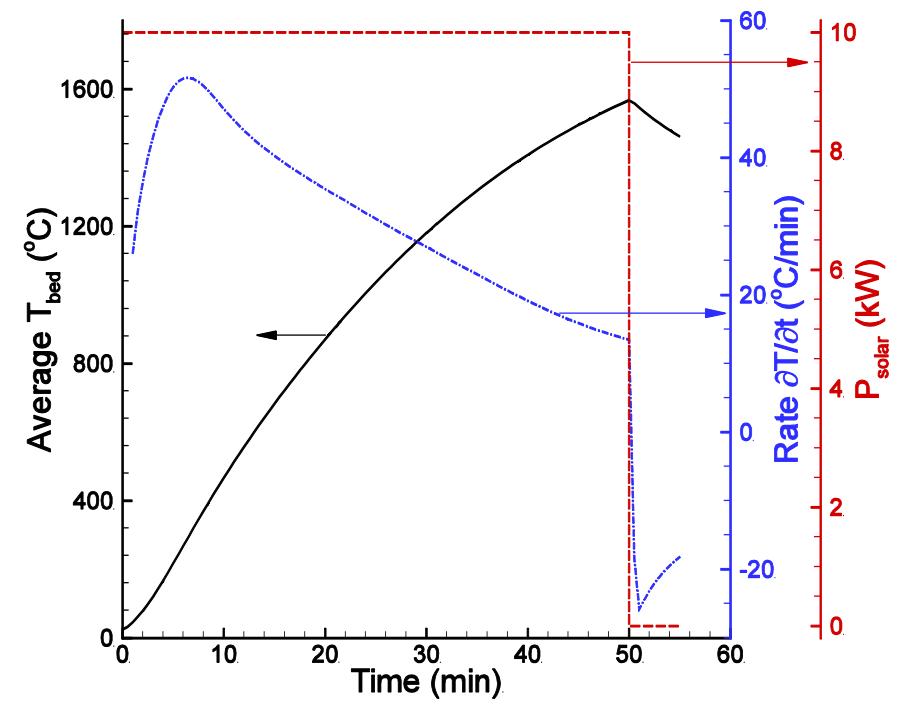

Fig. 8. Variations of the average bed temperature, $T_{\text {bed }}$, its rate of change, and the solar power, $P_{\text {solar, }}$ with time.

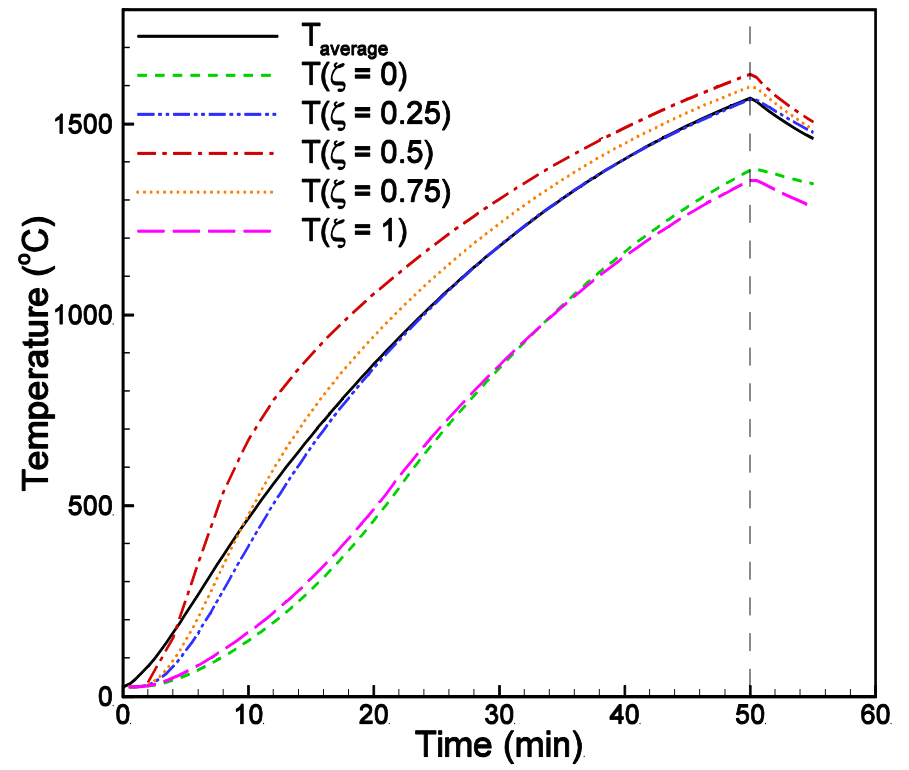

Fig. 9. Local temperature variations with time along the centerline of Absorber 1. 


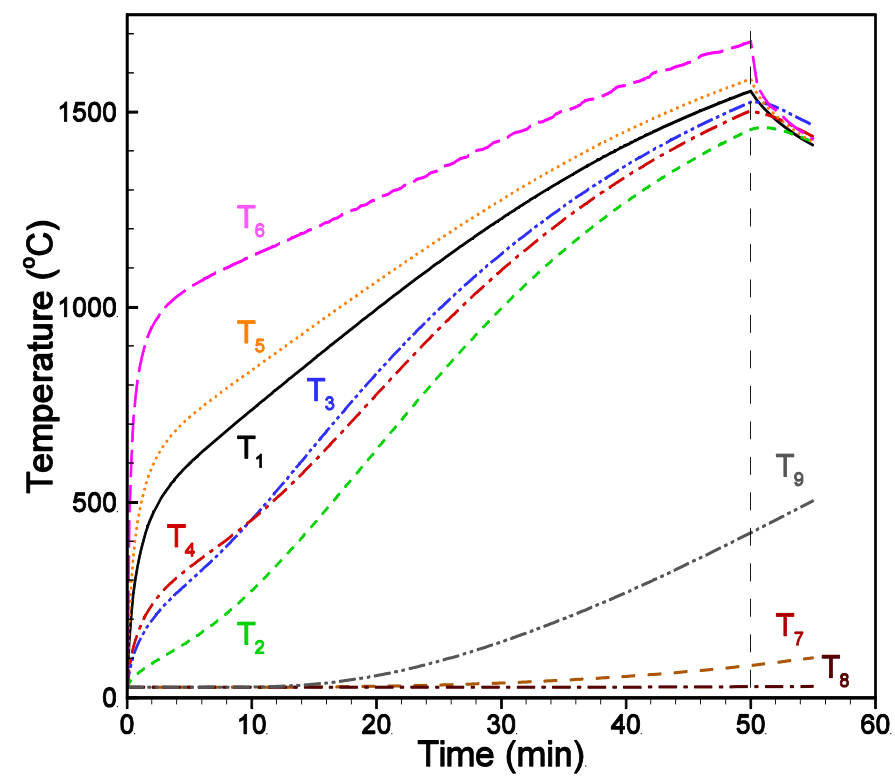

Fig. 10. Local temperature variations with time on the inner cavity surface and within the insulation layers (see Fig. 2(a) for the locations of $T_{1}-T_{9}$ ).

The temperature distributions on the central cross-sectional $r-z$ plane of the solar reactor at times $t=30 \mathrm{~min}, 40 \mathrm{~min}, 50 \mathrm{~min}$, and $55 \mathrm{~min}$ are shown in Fig. 11 (a-d), respectively. As previously noted, the aperture is open to the incident flux when $t \leq 50 \mathrm{~min}$ (Fig. 11 (a-c)). It is closed for $t>50 \mathrm{~min}$ (Fig. 11 (d)). For the cavity-receiver, the temperature hot-spots are observed on the inner surfaces, and the temperatures drop to their minimum values on the outer surfaces of the insulation layer, indicating that the cavity is very well insulated. In addition, the thickness of thermal diffusion in the insulation layers due to heat conduction increases with time as shown in Figs. 11 (a-d). Within the absorbers, the temperature in the reactive bed increases when the solar power is supplied and near uniform distribution is observed in Fig. 11 (c). The bed temperature drops when the power is turned off. 


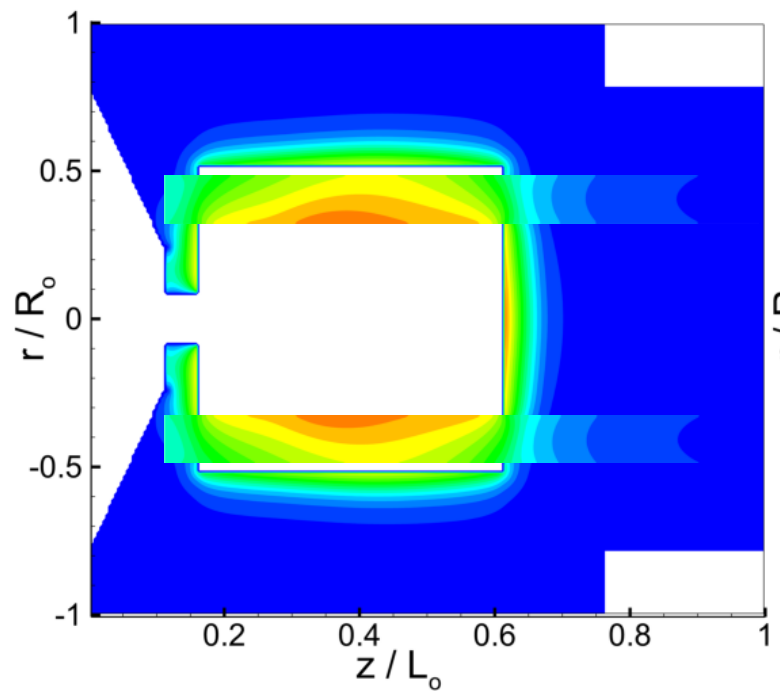

(a)

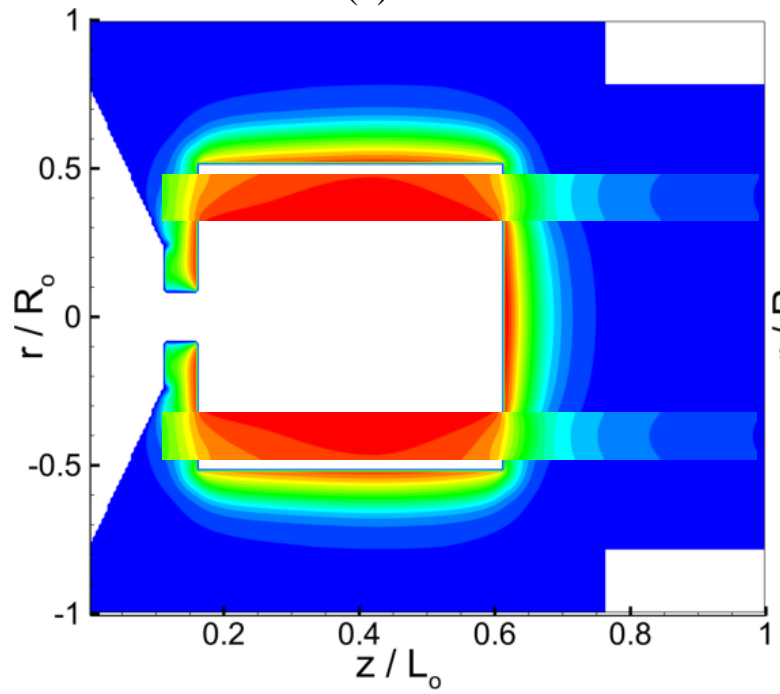

(c)

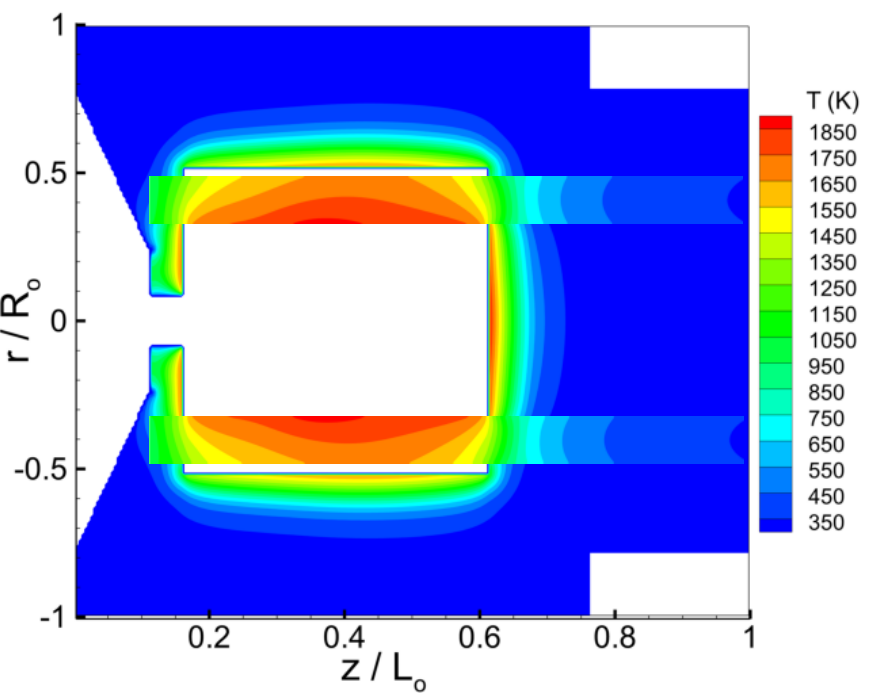

(b)

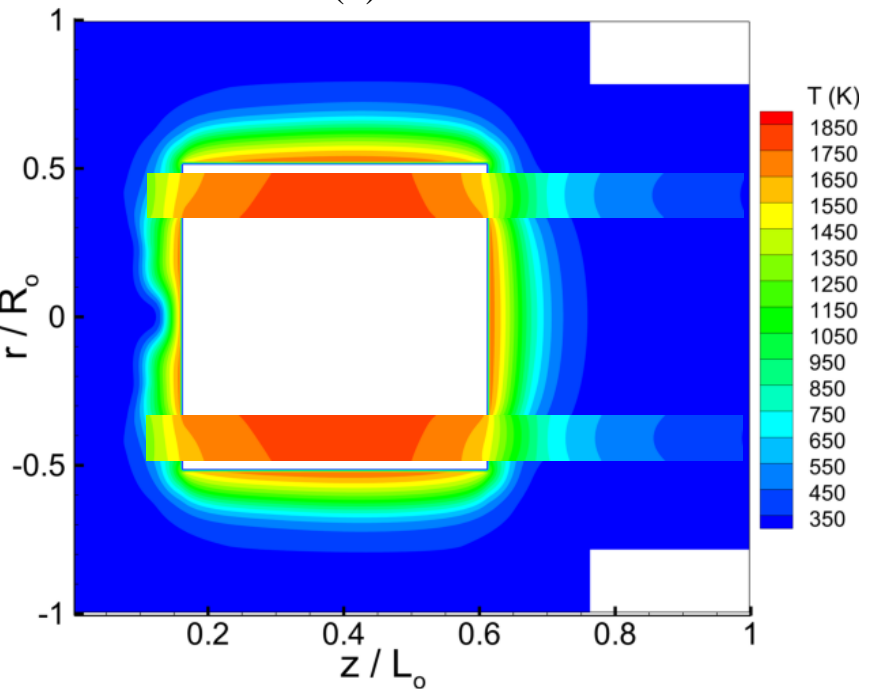

(d)

Fig. 11. Temperature distributions on the central $r-z$ plane of the solar reactor at (a) $t=30 \mathrm{~min}$, (b) $t=40 \mathrm{~min}$, (c) $t=50 \mathrm{~min}$, and (d) $t=55 \mathrm{~min}$ (see Figs. 8-10 for the time evolution).

To further investigate the surface flux and temperature distributions of the absorbers, Figs. 12 and 13 show the respective net heat flux and temperature contours, and Fig. 14 shows the temperature profiles at $\zeta=0,0.25,0.5,0.75$, and 1 on the tubular outer surface of Absorber 1 . The selected distributions are also at the times $t=30 \mathrm{~min}, 40 \mathrm{~min}, 50 \mathrm{~min}$ and $55 \mathrm{~min}$. Note that in Fig. 13 the distribution is shown on the full tubular surface, including the tube section at the bottom of thickness $w$, the bottom insulation section $\left(L_{\mathrm{ins}, 1}\right)$, the reactive bed section $\left(L_{\mathrm{bed}}\right)$, and the top insulation section $\left(L_{\mathrm{ins}, 2}\right)$ (see Fig. 2(c)). The distributions in Figs. 12-14 are close to 
symmetric about the line at $\theta=0$ (see Fig. 2 (b)). It is noted in Fig. 12 that while the front part of the tubular surface exposed to the incident flux is absorbing high flux, the net flux on the back side is much smaller during the ramp-up $(t \leq 50 \mathrm{~min})$; the majority of the tube surface is emitting radiative flux $\left(q_{\mathrm{tube}}^{\mathrm{net}}<0\right)$ at high temperatures during the cooling stage $(t>50 \mathrm{~min})$. Consistent with the centerline temperature evolutions in Fig. 9, the results in Figs. 13 and 14 clearly show that the "hot spot" is near the center of the bed at $\zeta=0.5$. The heat is gradually conducted to the insulation sections inside the tube as shown in Figs. 11 and 13, and the surface temperature becomes more and more uniform in the $\theta$-direction in Figs. 13 and 14.

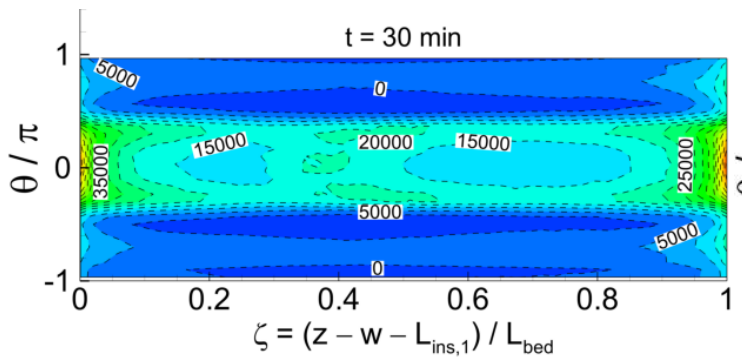

(a)

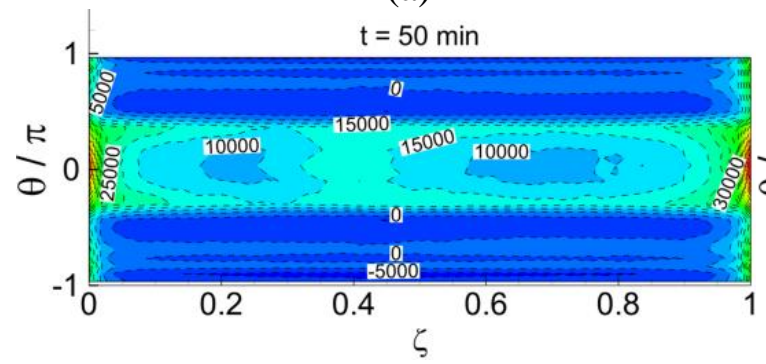

(c)

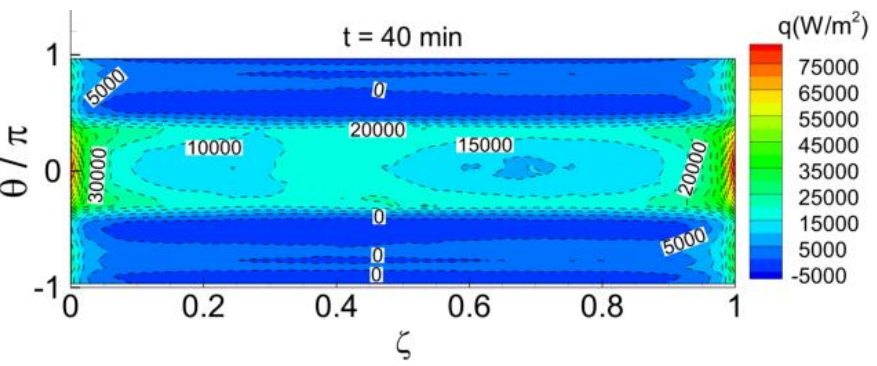

(b)

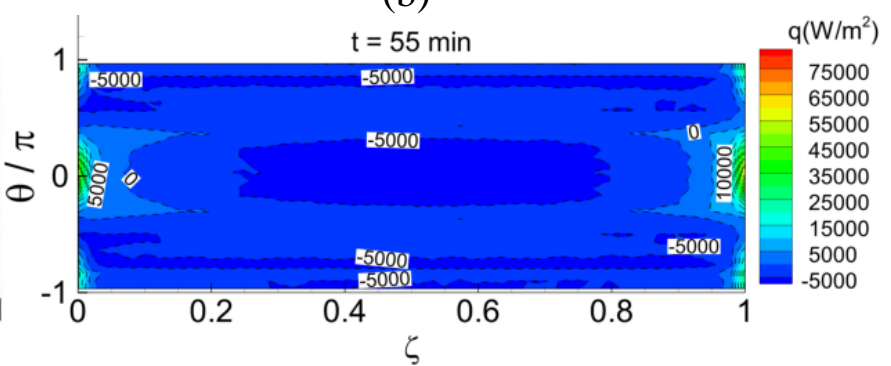

(d)

Fig. 12. Net heat flux distributions on the absorber surface at (a) $t=30 \mathrm{~min}$, (b) $t=40 \mathrm{~min}$, (c) $t$ $=50 \mathrm{~min}$, and (d) $t=55 \mathrm{~min}$.

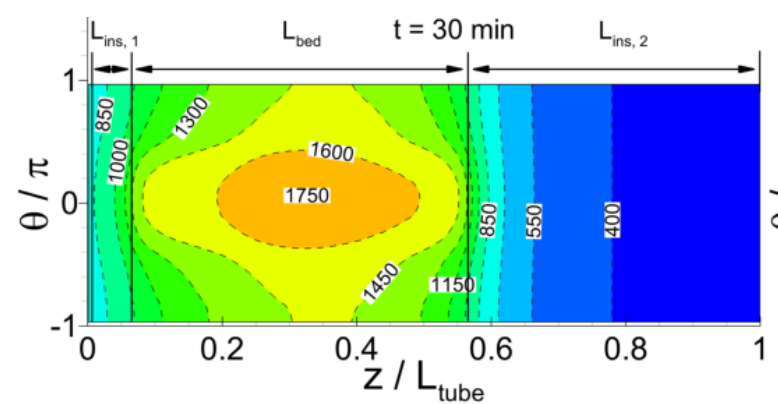

(a)

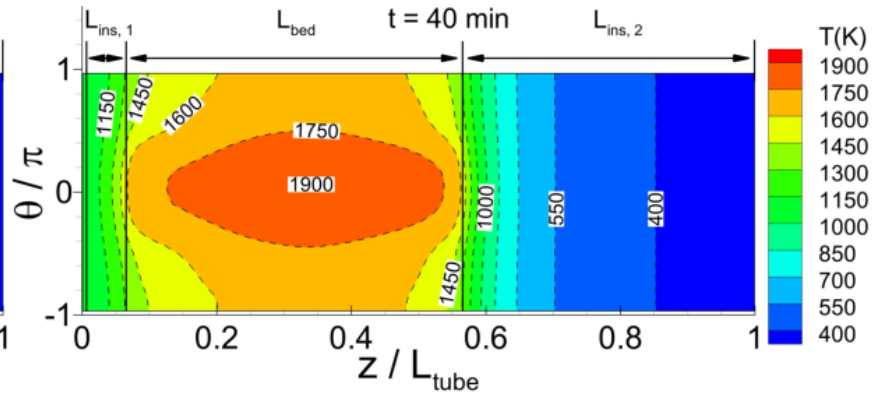

(b) 


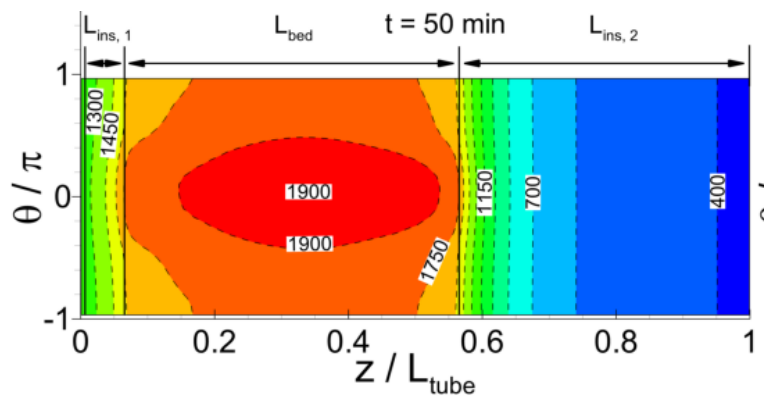

(c)

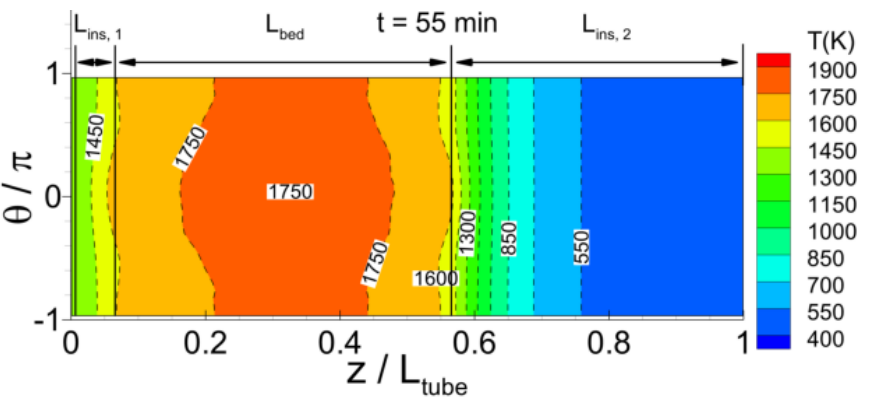

(d)

Fig. 13. Temperature distributions on the absorber surface at (a) $t=30 \mathrm{~min}$, (b) $t=40 \mathrm{~min}$, (c) $t$ $=50 \mathrm{~min}$, and $(\mathrm{d}) t=55 \mathrm{~min}$.

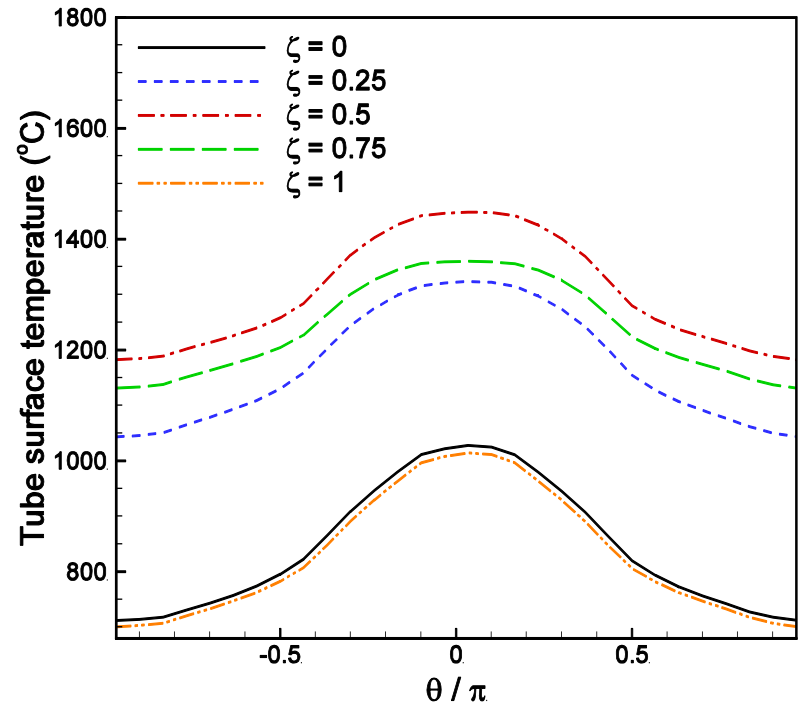

(a)

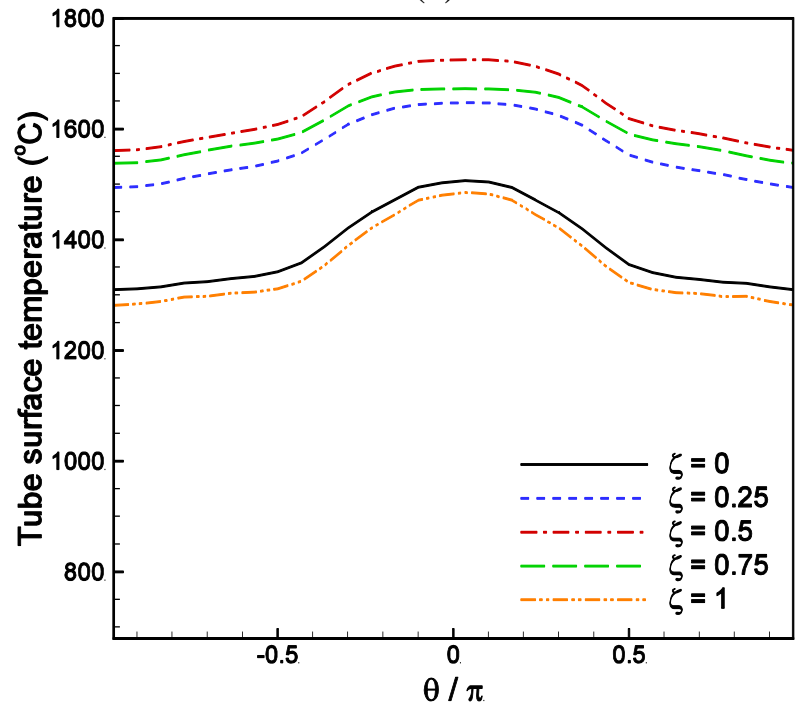

(c)

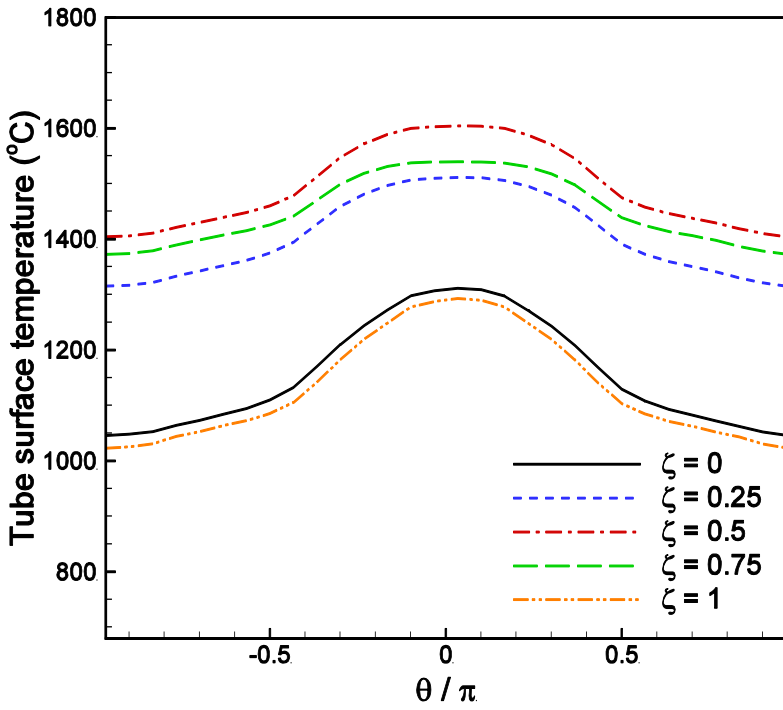

(b)

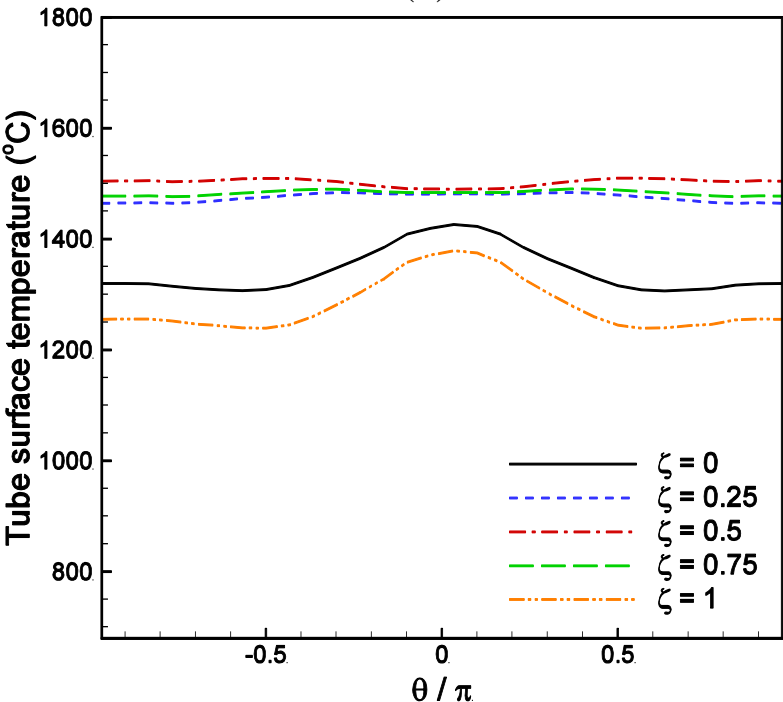

(d)

Fig. 14. Temperature profiles at the specific axial coordinates on the absorber surface at (a) $t=$ $30 \mathrm{~min}$, (b) $t=40 \mathrm{~min}$, (c) $t=50 \mathrm{~min}$, and (d) $t=55 \mathrm{~min}$. 
The interior temperature distribution of Absorber 1 on the central $x-z$ and $y-z$ planes (see Fig. 2(b) for the coordinate system) at those instants are presented in Figs. 15 and 16, respectively. Similar to those in Fig. 13, the results are presented on the full tubular surface. It is also noted that the $x$ and $z$ axes in Figs. 15 and 16 are scaled by the respective $R_{\text {tube }}$ and $L_{\text {tube }}$ $\left(>>R_{\text {tube }}\right.$ ) for clarity. The contours in Fig. 15 are near symmetric towards the centerline at $x=0$. The temperature hot spots in Fig. 16 are at the bottom $y=-R_{\text {tube, }}$ i.e., at $\theta=0$ as seen in Fig. 13 and 14 , on the tube surface.

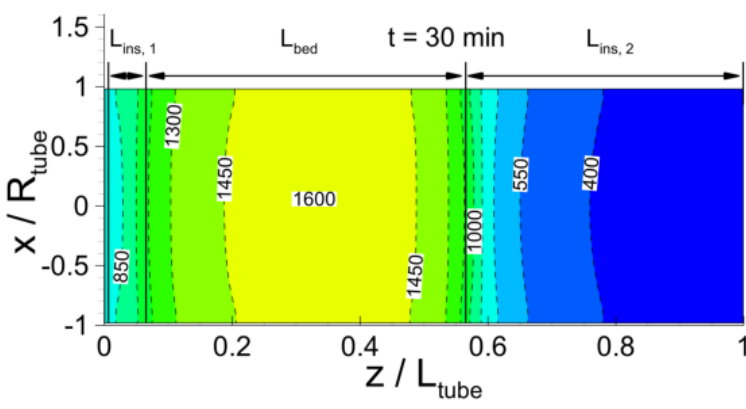

(a)

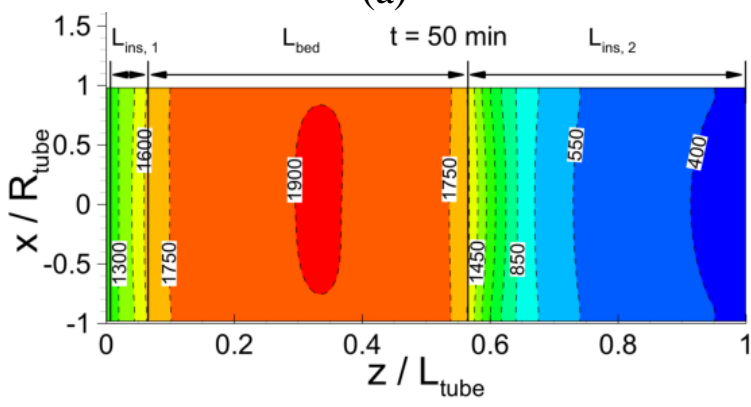

(c)

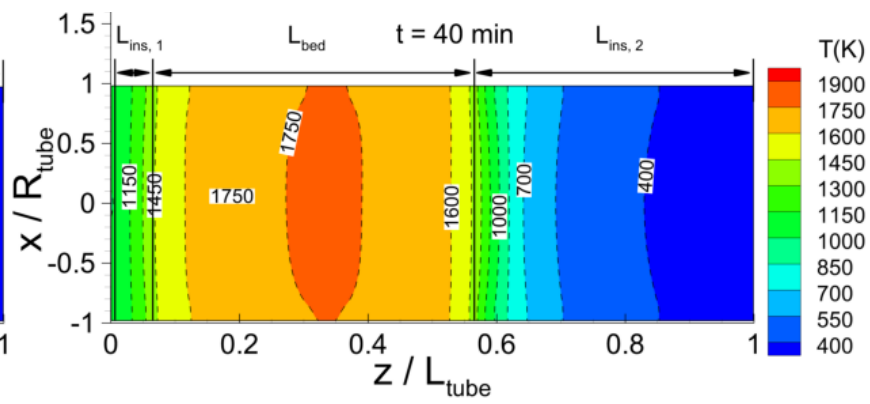

(b)

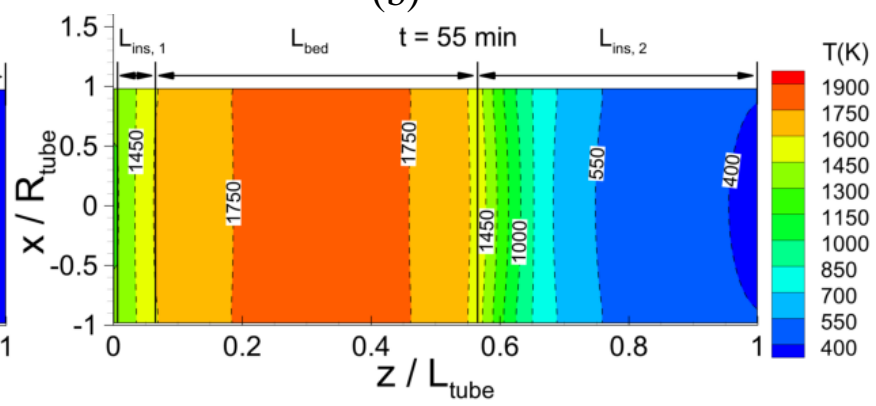

(d)

Fig. 15. Temperature distributions on the central $x-z$ plane inside the absorber at (a) $t=30 \mathrm{~min}$, (b) $t=40 \mathrm{~min}$, (c) $t=50 \mathrm{~min}$, and (d) $t=55 \mathrm{~min}$.

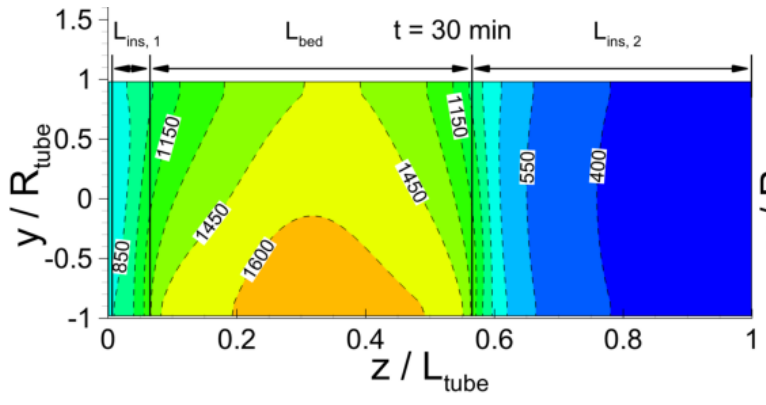

(a)

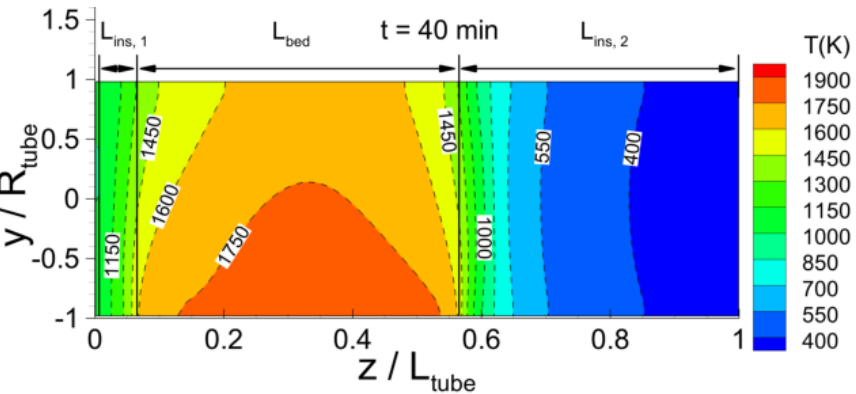

(b) 


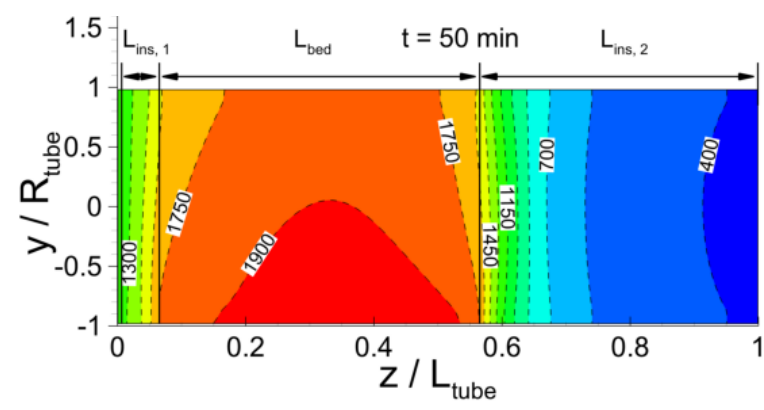

(c)

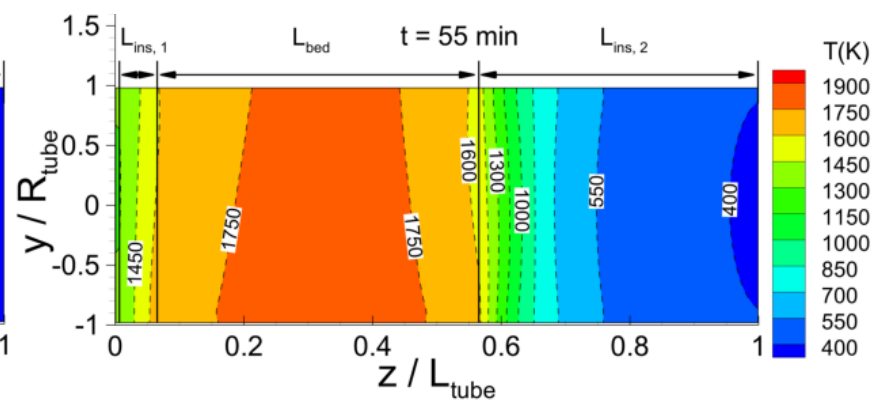

(d)

Fig. 16. Temperature distributions on the central $y-z$ plane inside the absorber at (a) $t=30 \mathrm{~min}$, (b) $t=40 \mathrm{~min}$, (c) $t=50 \mathrm{~min}$, and (d) $t=55 \mathrm{~min}$.

To further illustrate the dynamics of heating process within the reactive bed, Figs. 17-20 show the contours on the cross-sectional $x-y$ planes of Absorber 1 along different axial locations from the bottom of the bed at various instants. The lattice grid is also given in Fig. 17 (a). Along with the results in Figs. 15 and 16, the dynamic changes of the temperature distributions are clearly captured. Clearly, as heating progresses, the temperature increases and its uniformity across the tube cross section improves. However, the tube ends remain relatively cold.

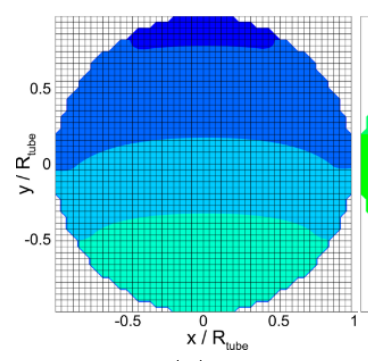

(a)

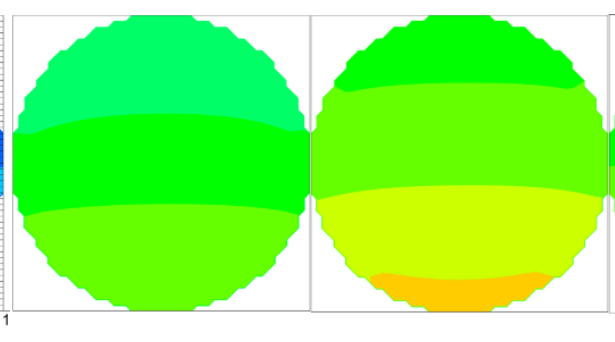

(b) (c)

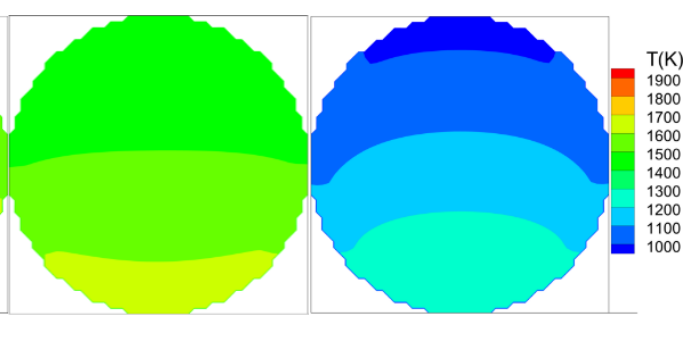

(d) (e)

Fig. 17. Temperature distributions on the central $x-y$ plane at (a) $\zeta=0$, (b) $\zeta=0.25$, (c) $\zeta=0.5$, (d) $\zeta=0.75$, and (e) $\zeta=1$ inside the absorber when $t=30 \mathrm{~min}$.

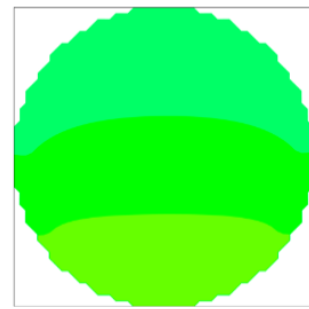

(a)

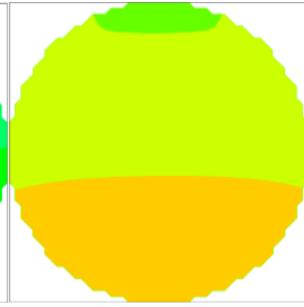

(b)

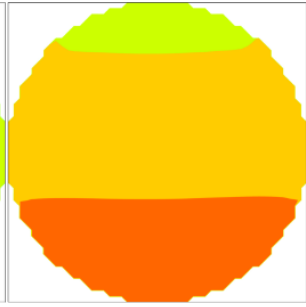

(c)

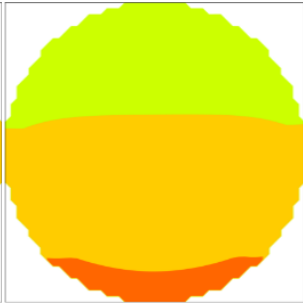

(d)

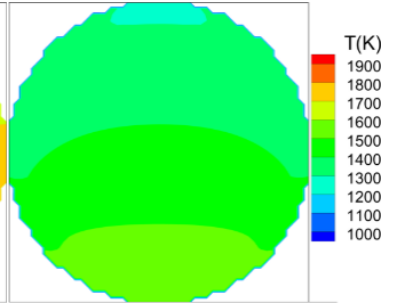

(e)

Fig. 18. Temperature distributions on the central $x$-y plane at (a) $\zeta=0$, (b) $\zeta=0.25$, (c) $\zeta=0.5$, (d) $\zeta=0.75$, and (e) $\zeta=1$ inside the absorber when $t=40 \mathrm{~min}$. 


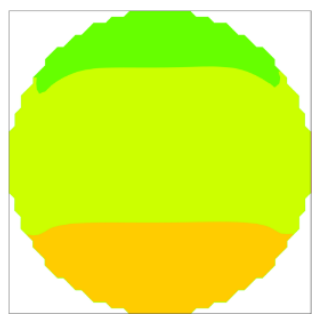

(a)

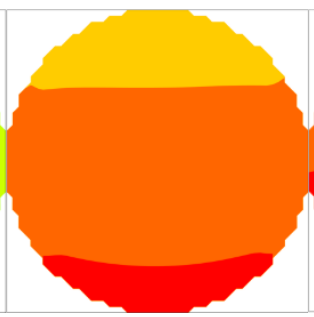

(b)

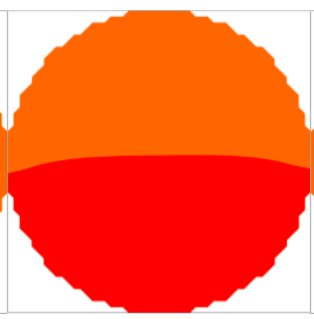

(c)

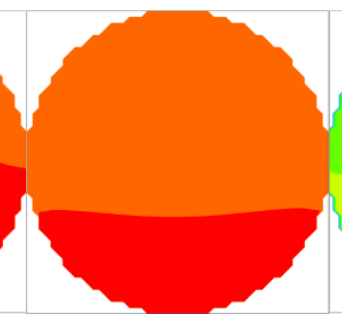

(d)

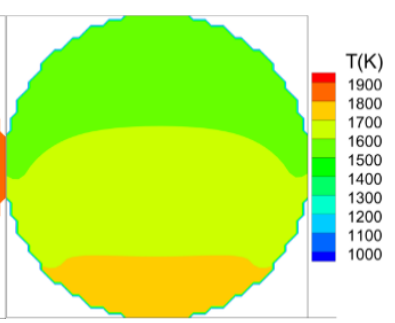

(e)

Fig. 19. Temperature distributions on the central $x-y$ plane at (a) $\zeta=0$, (b) $\zeta=0.25$, (c) $\zeta=0.5$, (d) $\zeta=0.75$, and (e) $\zeta=1$ inside the absorber when $t=50 \mathrm{~min}$.

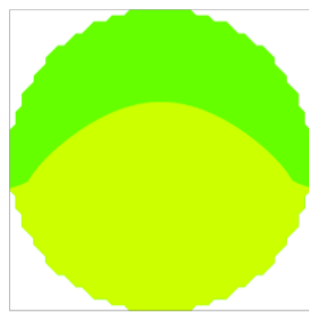

(a)

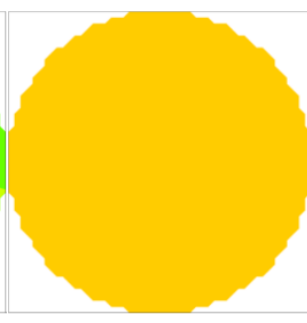

(b)

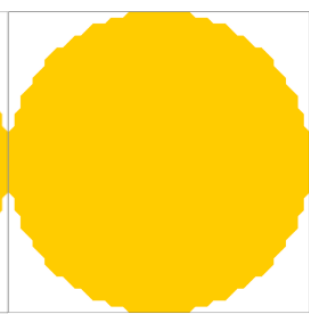

(c)

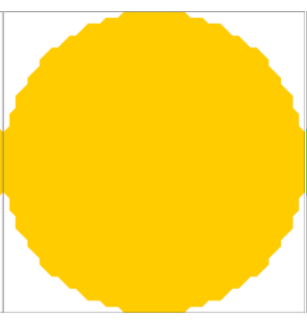

(d)

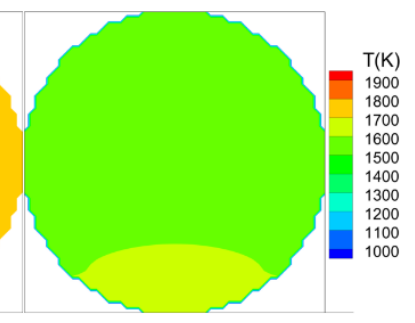

(e)

Fig. 20. Temperature distributions on the central $x-y$ plane at (a) $\zeta=0$, (b) $\zeta=0.25$, (c) $\zeta=0.5$, (d) $\zeta=0.75$, and (e) $\zeta=1$ inside the absorber when $t=55 \mathrm{~min}$.

To elucidate the energy budget in the solar reactor, the dynamic splitting of the total 10 $\mathrm{kW}$ incident solar power in the cavity is shown in Fig. 21 for $t \leq 50 \mathrm{~min}$. For each component, the power is calculated from the product of the net heat flux and the local segment area on the tube surfaces inside the cavity or the inner surface of the cavity, including the horizontal cylindrical wall and the vertical front and back plates. The heat loss from the aperture is computed from the MCRT modeling for both the incident rays and those due to radiative emission from all surfaces. The majority of the solar power is absorbed by the 14 tubes and the portion decreases with time as they are heated up. The heat loss from the aperture increases considerably as the reactor temperature increases. At the end of $t=50 \mathrm{~min}$, the aperture heat loss represents $16.8 \%$ of the incident $10 \mathrm{~kW}$ solar power. 


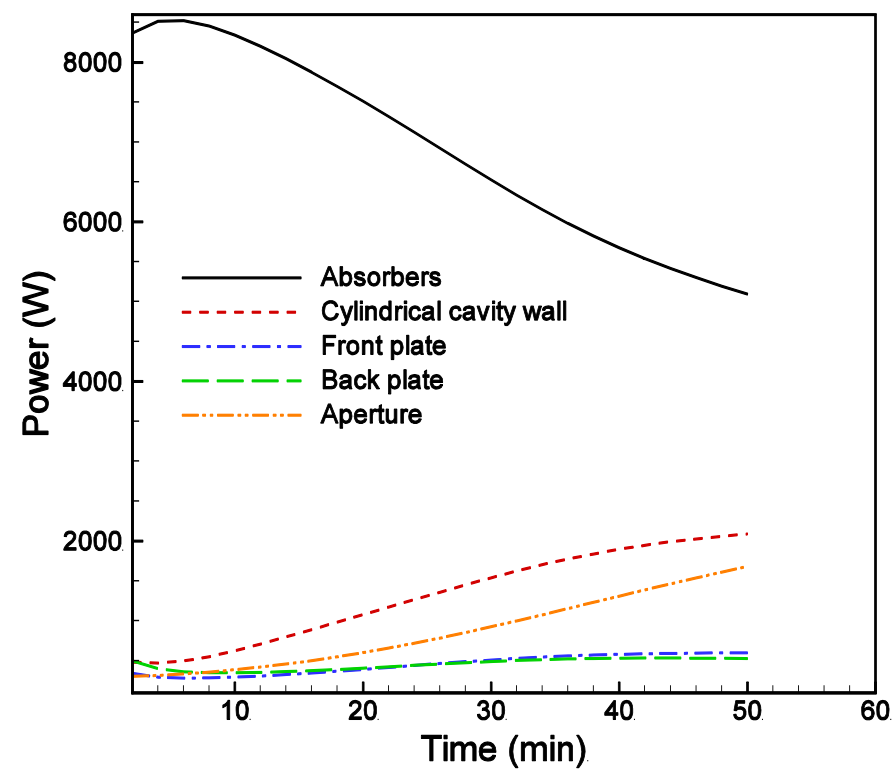

Fig. 21. Instant energy balance in the cavity-receiver during the "on-sun" period.

The prediction of $\mathrm{O}_{2}$ production rate and its cumulative yield during the reduction step at $t \leq 50$ min is shown in Fig. 22. A constant $\mathrm{O}_{2}$ partial pressure, $P_{\mathrm{O} 2}$, typical of dry pump operation of $1.32 \times 10^{-4} \mathrm{~atm}$ is assumed during the whole reduction process with the vacuum pump applied. Similar simulations are conducted for another two cases with different $P_{\mathrm{O} 2}$ values, and the $\mathrm{O}_{2}$ yield values are shown in Fig. 23. The maximum $\mathrm{O}_{2}$ rate is $0.254 \mathrm{ml} \cdot \mathrm{min}^{-1} \cdot \mathrm{g}^{-1} \mathrm{CeO}_{2}$ in Fig. 22, and the $\mathrm{O}_{2}$ yield values are $2.49 \mathrm{ml} \cdot \mathrm{g}^{-1}, 3.52 \mathrm{ml} \cdot \mathrm{g}^{-1}$, and $4.79 \mathrm{ml} \cdot \mathrm{g}^{-1} \mathrm{CeO}_{2}$ for the three cases. Assuming a stoichiometric ratio of $n_{\mathrm{H}_{2}}: n_{\mathrm{O}_{2}}=2: 1$, the $\mathrm{H}_{2}$ production for $\mathrm{H}_{2} \mathrm{O}$ splitting can be predicted, and the solar-to-fuel conversion efficiency can be calculated according to the following

$$
\eta_{\text {solar-to-fuel }}=\frac{\mathrm{HHV}_{\text {fuel }} n_{\text {fuel }}}{Q_{\text {solar }}+Q_{\text {pump }}+E_{\text {penalties }}}
$$

where HHV denotes the higher heating value of the fuel $\left(\mathrm{HHV}=286 \mathrm{~kJ} \cdot \mathrm{mol}^{-1}\right.$ for $\left.\mathrm{H}_{2}\right), n$ is the total moles of fuel produced, $Q_{\text {solar }}$ is the total input solar energy, $Q_{\text {pump }}$ is the heat equivalent for pumping gas with the vacuum pump, and $E_{\text {penalties }}$ includes all other energy required, such as to make steam for the oxidation step and the energy derived from consumption of inert gases. 
$E_{\text {penalties }}$ is typically much smaller compared to $Q_{\text {solar }}[15,16]$. Although not included in the simulation, it is assumed that the heat recuperated from the outer surface of the reactor could be used to supply the energy required for $E_{\text {penalties }}[22,23]$.

Determination of the heat equivalent to the vacuum pump work requires both the pump efficiency of converting electricity to mechanical work $\left(\eta_{1}\right)$, as well as the heat to electrical energy conversion efficiency $\left(\eta_{2} \sim 0.4\right)$. Assuming that the vacuum pump operates at near isothermal conditions, $T_{\text {pump }}$, the required pumping work for the $\mathrm{O}_{2}$ stream is

$$
W_{\text {pump }}=n_{\mathrm{O}_{2}} R T_{\text {pump }} \ln \left(P_{0} / P_{\mathrm{O}_{2}}\right),
$$

where $R$ is the gas constant and $P_{0}$ is the ambient pressure. The corresponding heat equivalent is

$$
Q_{\text {pump }}=W_{\text {pump }} /\left(\eta_{1} \eta_{2}\right) \text {. }
$$

A constant efficiency with $\eta_{1}=0.40$ and $\eta_{2}=0.40$ was used in [42]. Bulfin et al. [43] and Brendelberger and Sattler [44] pointed out that the pumping efficiency would decrease at lower pressures based on their analyses of some commercial vacuum systems. A power law to describe the relationship of pump efficiency to pressure, $P$, with $\eta_{1}=P^{0.544}$, was presented in [43]. However, they also reasoned that vacuum pumps operating at lower pressures have not been designed for efficiency, and therefore could be more efficient. A more optimistic semi-empirical relationship was given in [44] for $1 \mathrm{~Pa}<P<100 \mathrm{kPa}$

$$
\eta_{1}=0.07 \log \left(P / P_{0}\right)+0.4 \text {. }
$$

The above relationship, Eq. (38), was also implemented in [45]. In the present work, we also use Eq. (38) combined with the assumptions of $\eta_{2}=0.4$ and $T_{\text {pump }}=100{ }^{\circ} \mathrm{C}$ for $Q_{\text {pump. }}$. In our experimental testing, an Ebara vacuum pump is used, and its maximum electric power at the ultimate pressure $10^{-5}$ bar is $1.1 \mathrm{~kW}$ [46]. For the 20 min reduction period shown in Table 3 
below, a possible maximum $Q_{\text {pump }}$ is thus $Q_{\text {pump_max }}=(1.1 \times 20 \times 60) / 0.4=3300 \mathrm{~kJ}$. A crosscheck of the result in the third case in Table 3 indicates that Eq. (38) is reasonably accurate, and is thus used for all the other cases presented. Further exploration of the potential for improving vacuum pumping efficiency is warranted to optimize the choice of operating pressure.

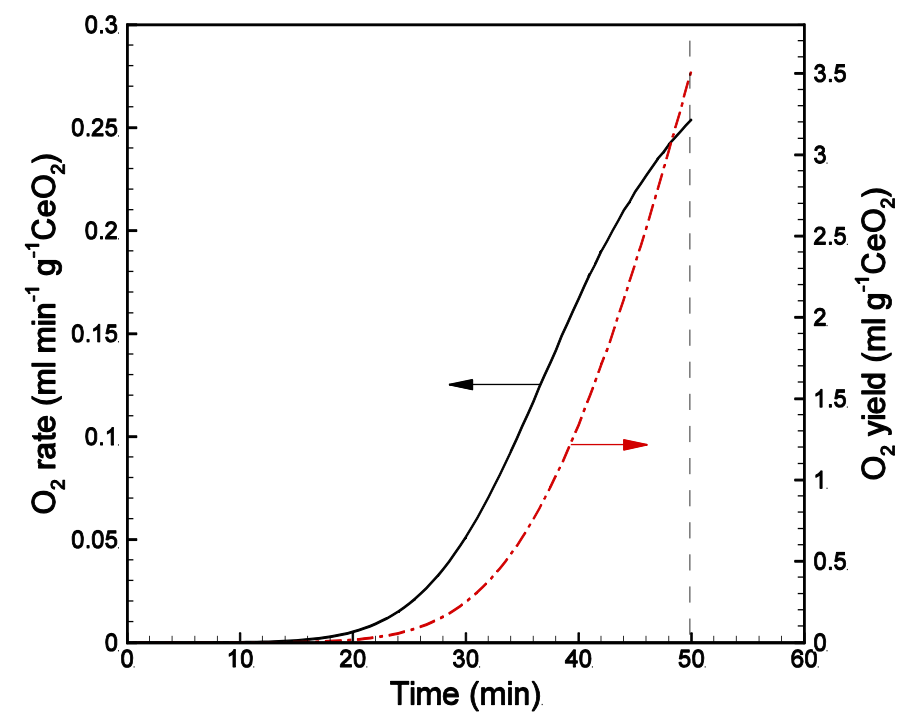

Fig. 22. Simulated $\mathrm{O}_{2}$ rate and yield with time during the first reduction step with $\mathrm{O}_{2}$ partial pressure $P_{\mathrm{O} 2}=1.32 \times 10^{-4} \mathrm{~atm}$.

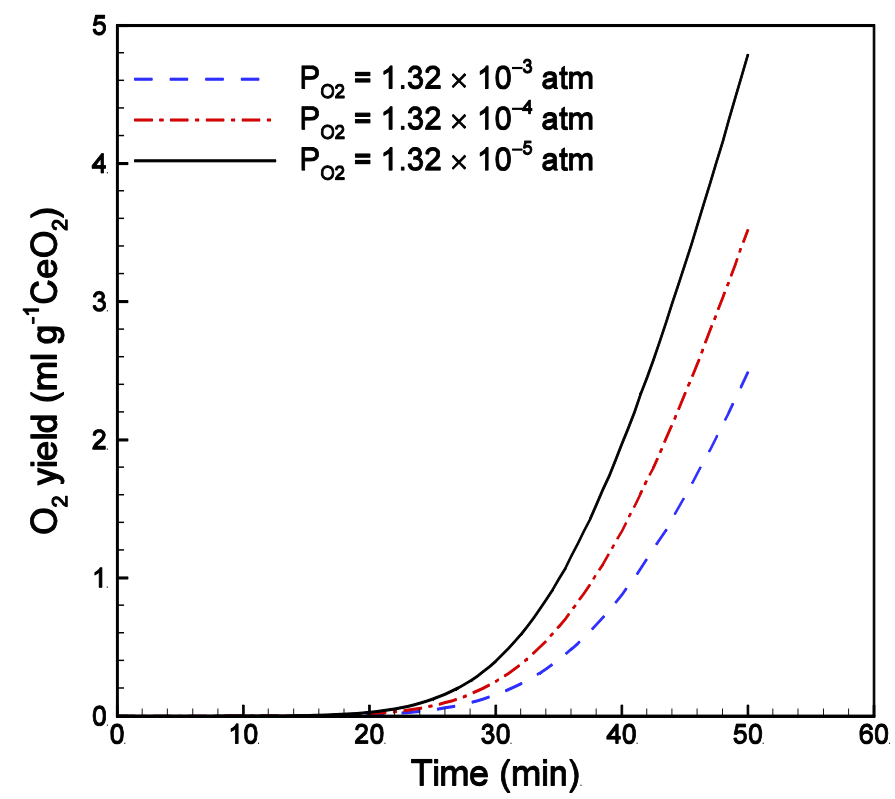

Fig. 23. Simulated $\mathrm{O}_{2}$ yield with time during the first reduction step when different partial pressures of $\mathrm{O}_{2}$ are maintained. 
Table 3 summarizes the predicted solar-to-fuel efficiencies for the three cases with the $\mathrm{O}_{2}$ partial pressures in Fig. 23. The corresponding averaged $\mathrm{CeO}_{2}$ extent of reduction, $\delta$, and the nominal bed temperature calculated according to Eq. (19) are also listed in Table 3. According to the temperature profiles in Figs. 8 and 9, it is assumed that $T_{\text {bed }}$ will drop to about $1300{ }^{\circ} \mathrm{C}$ during the "off-sun" oxidation step, and thus the duration of the "on-sun" period with full power (10 $\mathrm{kW}$ ) is about $20 \mathrm{~min}$ for the bed to reach the same temperature as that at $t=50 \mathrm{~min}$. Table 3 also includes the estimated efficiencies if $t_{\text {on-sun }}=15 \mathrm{~min}$, and the same production is achievable, i.e., with new reactive materials explored that are able to be thermally reduced at lower temperatures and with similar thermophysical properties and redox cycling capability as ceria.

The results in Table 3 indicate that in order to achieve high energy conversion efficiency $5 \% \sim 10 \%$, the high reduction temperature $\left(>1550{ }^{\circ} \mathrm{C}\right)$, vacuum-pump-driven low partial pressure of $\mathrm{O}_{2}\left(<10^{-3} \mathrm{~atm}\right)$, and also high oxidation temperature $\left(>1300^{\circ} \mathrm{C}\right)$ are essential for a solar thermochemical reactor on the order of $10 \mathrm{~kW}_{\text {th }}$ or higher. Both the high temperature and near vacuum pressure are necessary for effective thermal reduction; while the high oxidation temperature is not favorable for the reaction from the thermodynamic prospects, it would enable fast kinetics and is crucial to reduce the energy input in the next reduction step since a significant amount of solar power is needed to heat up the reactor again after cooling during the off-sun oxidation step. 
Table 3. Prediction of solar-to-fuel efficiency $\eta_{\text {solar-to-fuel }}$ at different $P_{\mathrm{O} 2}$ values.

\begin{tabular}{c|c|c|c|c|c|c|c}
\hline$P_{\mathrm{O} 2}(\mathrm{~atm})$ & $\begin{array}{c}\mathrm{O}_{2} \text { released } \\
(\mathrm{mol}, 14 \text { tubes })\end{array}$ & $\begin{array}{c}\text { Average } \delta \\
\mathrm{in} \mathrm{CeO}_{2-\delta}\end{array}$ & $\begin{array}{c}\mathrm{H}_{2} \text { production } \\
(\mathrm{mol}, 14 \text { tubes })\end{array}$ & $\begin{array}{c}\text { Nominal } \\
T_{\text {bed }}\left({ }^{\circ} \mathrm{C}\right)\end{array}$ & $\begin{array}{c}Q_{\text {solar }}(\mathrm{kJ}) \\
\left(t_{\text {on-sun }}=20\right. \\
(15) \text { min })\end{array}$ & $\begin{array}{c}Q_{\text {pump }} \\
(\mathrm{kJ})\end{array}$ & $\begin{array}{c}\text { Efficiency } \\
\eta_{\text {solar-to-fuel }}\end{array}$ \\
\hline $1.32 \times 10^{-3}$ & 1.089 & 0.038 & 2.179 & 1593 & $\begin{array}{c}12000 \\
(9000)\end{array}$ & 284.4 & $\begin{array}{c}5.07 \% \\
(6.71 \%)\end{array}$ \\
$1.32 \times 10^{-4}$ & 1.540 & 0.054 & 3.080 & 1578 & $\begin{array}{c}12000 \\
(9000)\end{array}$ & 838.0 & $\begin{array}{c}6.86 \% \\
(8.95 \%)\end{array}$ \\
$1.32 \times 10^{-5}$ & 2.096 & 0.074 & 4.191 & 1561 & $\begin{array}{c}12000 \\
(9000)\end{array}$ & 3174.9 & $\begin{array}{c}7.90 \% \\
(9.85 \%)\end{array}$ \\
\hline
\end{tabular}

\section{Conclusions}

The conversion of solar energy to chemical fuels using high-temperature solar thermochemical reactors is a very attractive concept. The two-step $\mathrm{CO}_{2}$ and $\mathrm{H}_{2} \mathrm{O}$ splitting for syngas production using metal oxide redox looping processes represents one of the most promising technologies for renewable and carbon neutral fuel production. Of all the challenges, the overarching one is to improve the solar-to-fuel conversion efficiency to make this technology economically viable and competitive. Heat transfer plays a significant role in the complex multimode and multiphysics transport phenomena in the solar reactor. Heat transfer modeling is able to provide guidance for optimizing reactor design and operation.

In this work, a transient heat transfer model is developed for high temperature solar thermochemical reactors by coupling the Monte-Carlo ray tracing based radiation model with the thermal lattice Boltzmann method based convection-diffusion model. Detailed simulation results are presented for the heating process and the first reduction step in a novel $10 \mathrm{~kW}$ solar reactor design that consists of a horizontal cavity-receiver, a windowless aperture, an array of 14 tubular absorbers, and 3 layers of insulation. The solar-to-fuel efficiencies are predicted, and the values 
on the order of $5 \%$ to $10 \%$ are achievable with the present reactor design. The required temperatures and $\mathrm{O}_{2}$ partial pressures are reasonably achievable.

The present model serves as a basis that can be extended to model the oxidation step and the redox cycling. Based on the present reactor design, a nominal $10 \mathrm{~kW}$ solar reactor has been fabricated and is currently under experimental testing at the University of Florida. Comparison of the modeling results with experimental tests will also be reported in future work in terms of the temperature evolution and $\mathrm{O}_{2}$ and $\mathrm{CO} / \mathrm{H}_{2}$ production.

\section{Acknowledgements}

This paper was prepared with the support of the U.S. Department of Energy, ARPA-E, under Award No. DEAR0000184.

\section{References}

[1] Steinfeld, A. Thermochemical production of syngas using concentrated solar energy. Ann. Rev. Heat Transfer, 2012, 15, 255-275.

[2] Kim, J., Johnson,T.A., Miller, J.E., Stechel, E.B., Maravelias, C.T. Fuel production from $\mathrm{CO}_{2}$ using solar-thermal energy: system level analysis. Energy Environ. Sci. 2012, 5, 84178429.

[3] Kräupl, S., Steinfeld, A. Experimental investigation of a vortex-flow solar chemical reactor for the combined $\mathrm{ZnO}$-reduction and $\mathrm{CH}_{4}$-reforming. ASME J. Sol. Energy Eng. 2001, 23, 237-243.

[4] Schunk, L.O., Haeberling, P., Wepf, S., Wuillemin, D., Meier, A., Steinfeld, A. A receiverreactor for the solar thermal dissociation of zinc oxide. ASME J. Sol. Energy Eng. 2008, 130, 021009-1-6.

[5] Hirsch, D., Zedtwitz, P., Osinga, T., Kinamore, J., Steinfeld, A. A new 75 kW high-flux solar simulator for high-temperature thermal and thermochemical research. ASME J. Sol. Energy Eng. 2003, 125, 117-120.

[6] Petrasch, J., Coray, P., Meier, A., Brack, M., Haberling, P., Wuillemin, D., Steinfeld, A. A novel $50 \mathrm{~kW}$ 11,000 suns high-flux solar simulator based on an array of xenon arc lamps. ASME J. Sol. Energy Eng. 2006, 129, 405-411.

[7] Müller, R., Lipiński, W., Steinfeld, A. Transient heat transfer in a directly-irradiated solar chemical reactor for the thermal dissociation of ZnO. Appl. Therm. Eng. 2008, 28, 524-531. 
[8] Abanades, S., Charvin, P., Flamant, G. Design and simulation of a solar chemical reactor for the thermal reduction of metal oxides: case study of zinc oxide dissociation. Chem. Eng. Sci. 2007, 62, 6323-6333.

[9] Kaneko, H., Miura, T., Fuse, A., Ishihara, H., Taku, S., Fukuzumi, H., Naganuma, Y., Tamaura, Y. Rotary-type solar reactor for solar hydrogen production with two-step water splitting process. Energ. Fuel. 2007, 21, 2287-2293.

[10] Kaneko, H., Ishikawa, Y., Lee, C., Hart, G., Stein, W., Tamaura, Y. Simulation study of Tokyo Tech rotary-type solar reactor on solar field test at CSIRO in Australia. Proc. of ASME 5th Int. Conf. Energ. Sust. 2011, ES2011-54568, 1-8.

[11] Diver, R.B., Miller, J.E., Allendorf, M.D., Siegel, N.P., Hogan, R.E. Solar thermochemical water-splitting ferrite-cycle heat engines. ASME J. Sol. Energy Eng. 2008, 130, 041001-18.

[12] Miller, J.E., Allendorf, M.D., Diver, R.B., Evans, L.R., Siegel, N.P., Stuecker, J.N. Metal oxide composites and structures for ultra-high temperature solar thermochemical cycles. $J$. Mater. Sci. 2008, 43, 4714-4728.

[13] Roeb, M., Neises, M., Säck, J.-P., Rietbrock, P., Monnerie, N., Dersch J., Schmitz, M., Sattler, C. Operational strategy of a two-step thermochemical process for solar hydrogen production. Int. J. Hyd. Energ. 2009, 34, 4537-4545.

[14] Roeb, M., Säck, J.-P., Rietbrock, P., Prahl, C., Schreiber, H., Neises, M., de Oliveira, L., Graf, D., Ebert, M., Reinalter, W., Meyer-Grünefeldt, M., Sattler, C., Lopez, A., Vidal, A., Elsberg, A., Stobbe, P., Jones, D., Steele, A., Lorentzou, S., Pagkoura, C., Zygogianni, Z., Agrafiotis, C., Konstandopoulos, A.G. Test operation of a $100 \mathrm{~kW}$ pilot plant for solar hydrogen production from water on a solar tower. Solar Energ. 2011, 85, 634-644.

[15] Chueh, W.C., Falter, C., Abbott, M., Scipio, D., Furler, P., Haile, S.M., Steinfeld, A. Highflux solar-driven thermochemical dissociation of $\mathrm{CO}_{2}$ and $\mathrm{H}_{2} \mathrm{O}$ using nonstoichiometric ceria. Science 2010, 330, 1797-1801.

[16] Furler, P., Scheffe, J., Gorbar, M., Moes, L., Vogt, U., Steinfeld, A. Solar thermochemical $\mathrm{CO}_{2}$ splitting utilizing a reticulated porous ceria redox system. Energ. Fuel. 2012, 26, 7051-7059.

[17] Marxer, D., Furler, P., Scheffe, J., Geerlings, H., Falter, C., Batteiger, V., Sizmann, A., Steinfeld, A. Demonstration of the entire production chain to renewable kerosene via solar thermochemical splitting of $\mathrm{H}_{2} \mathrm{O}$ and $\mathrm{CO}_{2}$. Energ. Fuel. 2015, 29, 3241-3250.

[18] Koepf, E., Advani, S., Steinfeld, A., Prasad, A.K. A novel beam-down, gravity-fed, soalr thermochemical receiver/reactor for direct solid particle decomposition: design, modeling, and experimentation. Int. J. Hyd. Energ. 2012, 37, 16871-16887.

[19] Lapp, J., Davidson, J.H., Lipiński, W. Heat transfer analysis of a solid-solid heat recuperation system for solar-driven nonstoichiometric redox cycles. ASME J. Sol. Energy Eng. 2013, 135, 031004-1-11.

[20] Martinek, J, Weimer, A.W. Design considerations for a multiple tube solar reactor. Solar Energ. 2013, 90, 68-83.

[21] Villasmil, W., Meier, A., Steinfeld, A. Dynamics modeling of a solar reactor for zinc oxide thermal dissociation and experimental validation using IR thermography. ASME J. Sol. Energy Eng. 2014, 136, 011015-1-11.

[22] Bader, R., Chandran, R.B., Venstrom, L.J., Sedler, S.J., Krenzke, P.T., De Smith, R.M., Banerjee, A., Chase, T.R., Davidson, J.H., Lipiński, W. Design of a solar reactor to split 
$\mathrm{CO}_{2}$ via isothermal redox cycling of ceria. ASME J. Sol. Energy Eng. 2015, 137, 031007-110.

[23] Furler, P., Steinfeld, A. Heat transfer and fluid flow analysis of a $4 \mathrm{~kW}$ solar thermochemical reactor for ceria redox cycling. Chem. Eng. Sci. 2015, 137, 373-383.

[24] Li, L., Singh, A., AuYeung, N., Mei, R., Petrasch, J., Klausner, J.F. Lattice Boltzmann simulation of high-diffusivity problems with application to energy transport in a hightemperature solar thermochemical reactor. Proc. of ASME 2013 Heat Transfer Summer Conf. 2013, HT2013-17555, 1-11.

[25] Klausner, J.F., Li, L., Singh, A., AuYeung, N., Mei, R., Hahn, D., Petrasch, J. The role of heat transfer in sunlight to fuel conversion using high temperature solar thermochemical reactors. Proc. of the 15th Int. Heat Transfer Conf. 2015, IHTC15-KN28, 1-30.

[26] Steinfeld, A. Apparent absorptance for diffusely and specularly reflecting spherical cavities. Int. J. Heat Mass Transf. 1991, 34, 1895-1897.

[27] Petrasch, J. Thermal modeling of solar chemical reactors: transient behavior, radiative transfer. MS Thesis 2002, ETH-Zürich, Switzerland.

[28] Modest M.F. Radiative Heat Transfer, Academic Press, 2003, $3^{\text {rd }}$ edition.

[29] Amhalhel, G., Furmański, P. Problems of modeling flow and heat transfer in porous media. J. Power Tech., 1997, 85, 55-88.

[30] Bulfin, B., Lowe, A.J., Keogh, K.A., Murphy, B.E., Luebben, O., Krasnikov, S.A., Shvets, I.V. Analytical model of $\mathrm{CeO}_{2}$ oxidation and reduction. J. Phys. Chem. C, 2013, 117, 24129-24137.

[31] Yoshida, H., Nagaoka, M. Multiple-relaxation-time lattice Boltzmann model for the convection and anisotropic diffusion equation. J. Comput. Phys. 2010, 229, 7774-7795.

[32] Li, L., Mei, R., Klausner, J.F. Boundary conditions for thermal lattice Boltzmann equation method. J. Comput. Phys. 2013, 237, 366-395.

[33] Li, L., Mei, R., Klausner, J.F. Heat transfer evaluation on curved boundaries in thermal lattice Boltzmann equation method. ASME J. Heat Transfer 2014, 136, 012403.

[34] Li, L., Mei, R., Klausner, J.F. Multiple-relaxation-time lattice Boltzmann model for the axisymmetric convection diffusion equation. Int. J. Heat Mass Transfer 2013, 67, 338-351.

[35] Li, L., Chen, C., Mei, R., Klausner, J.F. Conjugate heat and mass transfer in the lattice Boltzmann equation method. Phys. Rev. E 2014, 89, 043308.

[36] Guo, K., Li, L., Xiao, G., AuYeung, N., Mei, R. Lattice Boltzmann method for conjugate heat and mass transfer with interfacial jump conditions. Int. J. Heat Mass Transfer 2015, 88, 306-322.

[37] Singh, A.K., AuYeung, N.J., Randhir, K., Mishra, R., Allen, K.M., Petrasch, J., Klausner, J.F. Thermal reduction of iron oxide under reduced pressure and implications on thermal conversion efficiency for solar thermochemical fuel production. Ind. Eng. Chem. Res. 2015, 54, 6793-6803.

[38] McDanel Advanced Ceramic Technologies, Alumina Tubes and Rods, http://www.mcdanelceramics.com/tubes_rods.html, 2015.

[39] Zircar Zirconia, Inc. Alumina Boards, Discs \& Cylinders, TYPE Buster, http://zircarzirconia.com/products/type-buster-alumina-boards-cylinders/; Alumina \& Mullite Blanket, http://zircarzirconia.com/products/type-buster-blanket-mat/, 2015. 
[40] Zircar Ceramics, Inc. MICROSIL Microporous Insulation, http://www.zircarceramics.com/pages/microporusinsulation/microporous.htm, 2015

[41] Kaviany, M. Heat Transfer in Porous Media. In Rohnsenow, W. M., Hartnett, J. P., and Cho, Y. I., editors, Handbook of Heat Transport, McGraw-Hill, 3rd edition, 9.6-9.7, 1998.

[42] Ermanoski, I., Siegel, N.P., Stechel, E.B. A new reactor concept for efficient solarthermochemical fuel production. J. Sol. Energy Eng. 2013, 135, 031002.

[43] Bulfin, B., Call, F., Lange, M., Lubben, O., Sattler, C., Pitz-Paal, R., Shvets, I.V. Thermodynamics of $\mathrm{CeO}_{2}$ thermochemical fuel production. Energy Fuels 2015, 29, 10011009.

[44] Brendelberger, S., Sattler, C. Concept analysis of an indirect particle-based redox process for solar-driven $\mathrm{H}_{2} \mathrm{O} / \mathrm{CO}_{2}$ splitting. Solar Energy 2015, 113, 158-170.

[45] Lin, M., Haussener, S. Solar fuel processing efficiency for ceria redox cycling using alternative oxygen partial pressure reduction methods. Energy 2015, http://dx.doi.org/10.1016/j.energy.2015.06.006.

[46] EBARA Technologies, Inc. Technical data for Model EV-A10, http://www.ebarapm.eu/Model_EV-A.html, 2015. 